\title{
Time-Resolved Macromolecular Crystallography at Pulsed X-ray Sources
}

\author{
Marius Schmidt
}

Physics Department, University of Wisconsin-Milwaukee, Milwaukee, WI 53211, USA; m-schmidt@uwm.edu; Tel.: +1-414-229-4338

Received: 27 February 2019; Accepted: 18 March 2019; Published: 20 March 2019

\begin{abstract}
The focus of structural biology is shifting from the determination of static structures to the investigation of dynamical aspects of macromolecular function. With time-resolved macromolecular crystallography (TRX), intermediates that form and decay during the macromolecular reaction can be investigated, as well as their reaction dynamics. Time-resolved crystallographic methods were initially developed at synchrotrons. However, about a decade ago, extremely brilliant, femtosecond-pulsed X-ray sources, the free electron lasers for hard X-rays, became available to a wider community. TRX is now possible with femtosecond temporal resolution. This review provides an overview of methodological aspects of TRX, and at the same time, aims to outline the frontiers of this method at modern pulsed X-ray sources.
\end{abstract}

Keywords: time-resolved crystallography; serial femtosecond crystallography; Monte Carlo integration; beta-lactamase; bacterial phytochromes

\section{Introduction}

Time-resolved macromolecular crystallography (TRX) unifies structure determination with reaction dynamics. Structures that evolve along the reaction coordinate can be determined with near atomic resolution in concert with the kinetic mechanism using the same set of crystallographic data. In favorable cases, no other information is required. Ever since the first protein structure was determined, it has been the goal of structural biologists to observe how biological macromolecules perform their function in real time. Among their many functions, which range from ligand binding to signal transduction, catalytic activity is most important. TRX has come a long way from early approaches at second-generation synchrotron light sources in the 1980s [1-3] to experiments at fourth generation X-ray sources that feature femtosecond ( $\mathrm{fs}$ )-duration and extremely brilliant X-ray pulses [4-6]. At synchrotron light sources, the polychromatic Laue method [7] is mostly used. The broad bandwidth of the 'pink' X-rays allows the instantaneous collection of integrated reflection intensities. This is required as with the traditional rotation method [8], the time required to rotate the reflections through the Ewald sphere is too long to provide the required fast time-resolution. Complex software solutions needed to be developed to process the complicated, weak, and spatially overlapping macromolecular Laue data [9,10]. Lately, free electron lasers for hard X-rays (XFELs) have become available, which has propelled TRX to a new level. The enormous X-ray pulse intensities at these machines makes it possible to interrogate a tiny crystal with a single X-ray pulse that lasts only femtoseconds. This opens the previously unreachable ultrafast time scales to crystallography. As the XFEL pulses are quasi-monochromatic, new approaches to recover the integrated X-ray intensities from highly partial X-ray data were required. The integrated intensities are assembled from hundreds to thousands of observations for each individual reflection gathered from a large number (millions) of diffraction patterns. These patterns were collected from trillions of tiny crystals that were injected in serial fashion into the X-ray beam. This approach, called Monte-Carlo integration [11,12], enabled 
the collection of complete datasets of highly accurate reflection intensities suitable for de novo X-ray structure determination [13] and TRX experiments.

\section{Synchrotron Light Sources}

Synchrotron X-ray sources feature sub-ns X-ray pulses (around $100 \mathrm{ps)}$ that are well suited for TRX experiments. Undulator sources produce intense, hard X-ray radiation which can be tuned to around $12 \mathrm{keV}(\lambda \sim 1 \AA)$. Near atomic resolution with crystals much smaller than $50 \mu \mathrm{m}$ is feasible even at room temperatures [14]. Undulator radiation typically carries a bandwidth of a few percent (2-5\%) between $200 \mathrm{eV}$ and $500 \mathrm{eV}$. At third-generation synchrotrons such as the Advanced Photon Source (APS) at the Argonne National Laboratory in Lemont, IL, the number of photons per 100-ps pulse is on the order of $5 \times 10^{10}[15]$ in a $5 \%$ bandwidth. For exploiting this type of X-ray radiation, the Laue method [7] is employed. The advantage is that a substantial number of reflections ( $2-10 \%$ of reciprocal space) are excited simultaneously, and the integrated reflection intensity is collected (almost) instantaneously [16]. Since Laue reflection intensities can be scaled together by making use of the known spectral form of the incident $X$-ray radiation, only a few diffraction patterns, on the order of 50, are required for a complete dataset. Once the pink beam is monochromatized to typical values of about $0.01 \%$ bandwidth, (i) the overwhelming majority ( $>99 \%$ ) of X-ray photons are disregarded and (ii) largely partial reflections are collected. Reflection intensities cannot be scaled together unless the crystal is rotated to collect the integrated reflection intensity. When the time resolution is pushed to the single-pulse limit, the crystal is effectively fixed during the pulse duration; rotations and translations are frozen in space. Each diffraction pattern is either a Laue pattern or a monochromatic still, depending on the X-ray bandwidth employed. These are some of the constraints under which a TRX experiment must be designed. Complete datasets at synchrotrons consists of a small number of diffraction patterns, each produced from multiple X-ray pulses. They require relatively large crystals and multiple crystal settings. These requirements make a TRX experiment very tricky; newest developments attempt to overcome these limitations. This review covers some of the most recent advances.

\section{Free Electron Lasers}

The free electron lasers for hard X-rays (XFELs) changed the way TRX experiments were conducted. XFELs feature femtosecond X-ray pulses with $10^{12}-10^{13}$ hard X-ray photons $(>9 \mathrm{keV})$ per pulse. These photons come within a quasi-monochromatic bandwidth of about $0.1 \%$. Only those reflections that are lying on the Ewald sphere, and thus in reflection position, are excited by all X-ray photons available in the beam; the rest do not contribute to the diffraction pattern. The number of photons per $0.1 \%$ bandwidth (bw) in a single $\mathrm{X}$-ray pulse is more than three orders of magnitude higher at XFELs $\left(>10^{12}\right.$ photons $/ 0.1 \%$ bw) than at the synchrotron $\left(5 \times 10^{10}\right.$ photons $/ 5 \%$ bw or $10^{9}$ photons $\left./ 0.1 \% \mathrm{bw}\right)$. Accordingly, crystals smaller by three orders of magnitude might be probed by a single pulse. In addition, the laser-like properties of the XFEL allow loss-free focusing of the X-ray beam on small, nanometer-sized spots. As a result, sub-micrometer-sized crystals diffract well and produce high-resolution diffraction patterns from a single X-ray pulse $[17,18]$. However, after just one $\mathrm{X}$-ray pulse, the acceptable $\mathrm{X}$-ray dose deposited in the tiny crystal is exceeded by several order of magnitudes [19] and the crystal suffers substantial radiation damage. The ultrashort, femtosecond-long X-ray pulse ensures that the diffraction pattern is collected before the crystal is destroyed by X-ray damage [20]. The crystal is discarded and replenished by a new, pristine one. This led to the development of serial femtosecond (nano) crystallography (SFX) [17], where a large number of small crystals are injected one by one into the X-ray beam in random orientation. For this, a dense crystalline slurry is pumped through an injector nozzle device. The archetypical device is called a 'gas dynamic virtual nozzle' (GDVN) [21] that forms a jet of about $5 \mu \mathrm{m}$ in diameter. The crystals move in the jet with a speed of about $10 \mathrm{~m} / \mathrm{s}$ until they are interrogated by the X-ray pulse. Reflections from each microcrystal are highly partial due to the monochromaticity of the X-ray beam. Averaging over a large number of observations (typically on the order of 500 for each reflection) is 
required to obtain the integrated reflection intensity. This necessitates the collection of a large number (on the order of 40,000) diffraction patterns containing Bragg reflections, which need to be sorted out from a much larger number (a few million) of blank patterns that contain no reflections [22]. Since each and every microcrystal arrives at the $\mathrm{X}$-ray interaction region in random orientation, each diffraction pattern needs to be indexed anew [23]. Indexing rates were initially low, but have increased to $80 \%$ and higher due to software sophistication and advances in optimizing detector geometries. The number of microcrystals required for a complete dataset also depends on the pulse repetition rate of the X-ray light source. For example, the Linac Coherent Light Source (LCLS) located at the SLAC National Accelerator Laboratory in Menlo Park, CA, features a 120-Hz repetition rate. The use of 8-ms gaps between the X-ray pulses allows a large number of microcrystals to pass by without being interrogated by $\mathrm{X}$-rays. The jet volume passing by in $8 \mathrm{~ms}$ is about $1.6 \times 10^{-6} \mathrm{~mL}$, given the jet diameter of $5 \mu \mathrm{m}$ and speed of $10 \mathrm{~m} / \mathrm{s}$ mentioned above. Assuming a crystal density of $10^{11} / \mathrm{mL}, 160,000$ crystals will pass by, and only one is interrogated by the X-ray pulse. Moreover, the probability that an X-ray beam of $1-\mu \mathrm{m}$ diameter intersects a 1- $\mathrm{m}$ crystal in the jet is low, on the order of $5 \%$, even at high crystal volume densities. As a result, for a single diffraction pattern with Bragg reflections, about 3 million microcrystals are required. To obtain 50,000 patterns of which 40,000 can be indexed for a dataset, therefore, on the order of 150 billion $\left(1.5 \times 10^{11}\right)$ microcrystals are needed, which is actually $1.5 \mathrm{~mL}$ of the dense crystalline slurry mentioned. In reality, this number is higher due to experimental challenges, and lies on the order of $5 \mathrm{~mL}$, which contains about $100 \mathrm{mg}$ of protein and half a trillion $\left(0.5 \times 10^{12}\right)$ microcrystals.

To reduce the number of crystals required for a dataset, two strategies among many are immediately conceivable: (i) the jet speed can be reduced so that a smaller volume of dense crystalline slurry passes by, and (ii) the pulse repetition rate of the XFELs can be increased. Both strategies are successfully pursued. A device that produces a much slower jet was developed [24] that allows tightly spaced volumes to be interrogated by the low repetition rates of most XFELs. The device slowly (at $\mathrm{nL} / \mathrm{min}$ speeds) extrudes a viscous material containing microcrystals. This drives crystal consumption down to less than one milligram, even at the LCLS with its $120-\mathrm{Hz}$ pulse repetition. The first material, which was used to form the viscous jet, was a lipid that formed a lipidic cubic phase. The lipidic cubic phase has a viscosity comparable to toothpaste. Therefore, the injector device has been also called the 'toothpaste' injector. The 'toothpaste' injector was very successfully used for many membrane proteins, including the rhodopsins [25,26] and GPCRs [27,28]. At the Japanese XFEL, the Spring-8 Ångstrøm Compact X-ray LAser (SACLA), an injector system was developed that uses various viscous materials such as nuclear-grade grease (superlube) as jet material [29,30]. Crystals are extruded into the $30-\mathrm{Hz}$ repetition rate X-ray pulses at SACLA. This method has been successfully used for soluble $[31,32]$ and membrane protein crystals $[26,33]$. Other slow injectors rely on electric fields to produce a finely spun liquid jet [34].

High X-ray pulse repetition rates necessitate closely spaced electron bunches in the linear accelerator (LINAC). The displacement currents required to generate the electric fields to accelerate these bunches in the LINAC are substantial, which limit pulse repetition rates with warm copper technology. At cryogenic (liquid helium) temperatures, superconducting technology can provide repetition rates of up to MHz. The first superconducting XFEL is the European XFEL (EuXFEL) in Hamburg, Germany. The EuXFEL is designed to provide 10 pulse trains per second, where each pulse train ultimately consists of up to $2700 \mathrm{X}$-ray pulses at a repetition rate of $4.5 \mathrm{MHz}$ (with $200 \mathrm{~ns}$ between the pulses within the train). After a gap of about $99.5 \mathrm{~ms}$, the pulse train repeats. As a result, the EuXFEL will produce 27,000 pulses per second, which is more than two orders of magnitude faster than the LCLS. However, the X-ray camera that collects the Bragg patterns must operate at a $\mathrm{MHz}$ rate in order to separate the diffraction patterns produced by the individual pulses in the pulse trains. An appropriate camera, called the adaptive gain integrating pixel detector (AGIPD), has been developed that is capable of collecting diffraction patterns with a $4.5-\mathrm{MHz}$ frame rate [35]. It has been shown that MHz data collection is possible with the AGIPD and specially designed GVDNs that 
produce jets with $30-100 \mathrm{~m} / \mathrm{s}$ velocity [36,37]. At this velocity, subsequent pristine jet volumes are not, or only insignificantly, affected by X-ray pulses intersecting the jet further downstream. Still, there are 99.4-ms gaps between the pulse trains. As a result, about 100 million crystals per second pass by and are not interrogated by X-rays. However, if specifications are fully adhered to (27,000 X-ray pulses/s), the collection of a dataset will only take about $40 \mathrm{~s}$ (again assuming 40,000 indexed patterns with a hit rate of $5 \%$ and an indexing rate of $80 \%$ ). Note that the hit rate is only dependent on the crystal density in the jet and does not change despite the faster X-ray repetition rate. Consequently, only 4 billion microcrystals will be required for a dataset at the EuXFEL, as opposed to 150 billion at the LCLS. This jet also produces substantial waste during the 99.4-ms breaks between the pulse trains. A 'jet-on-demand' that only delivers crystals during the approximately half-millisecond-long X-ray pulse trains would reduce this waste by more than two orders of magnitude. Superconducting XFELs such as the LCLS-II with constant repetition rates (from a few $\mathrm{kHz}$ up to $1 \mathrm{MHz}$ ) would certainly reduce sample consumption even more and speed up data collection enormously. As the gaps between the X-ray pulses are $10 \mu \mathrm{s}$ at $100 \mathrm{kHz}$, a high-speed jet would not be necessary. With conventional jet velocities of about $10 \mathrm{~m} / \mathrm{s}, 100 \mu \mathrm{m}$ of jet material between the X-ray pulses would ensure that the next, fresh crystal is not affected by a previous X-ray pulse [36-39]. A sample reduction by a factor of 50 relative to the EuXFEL and almost a factor of 1000 relative to the LCLS operating at $120 \mathrm{~Hz}$ can be expected. Rather than consuming more than $100 \mathrm{mg}$ of sample at the LCLS, as required today, less than $0.1 \mathrm{mg}$ will be only required per dataset. At $100 \mathrm{kHz}$, the collection of a complete dataset will only take $10 \mathrm{~s}$ (assuming $5 \%$ hit rate and $80 \%$ indexing rate), and it should be possible to collect hundreds of datasets per hour. Since time-resolved experiments require comprehensive time-series of time-resolved X-ray data that may consist of a large number of complete datasets, high-repetition-rate XFELs such as the EuXFEL or upgrades to the LCLS are indispensable. Any low-repetition-rate method used to deliver crystals, such as the viscous ('toothpaste') jet, the fixed target [40], or providing drops on demand [41], cannot be used at high-repetition-rate XFELs unless they can be modified to cope with the enormous repetition rates. It is possible that droplets of liquid and/or viscous material could be injected directly into the $\mathrm{X}$-ray interaction region with high repetition rates using fast and precise instrumentation. This will allow the interrogation of soluble protein and membrane protein microcrystals alike. Then, the dream of following a biomolecular reaction with closely spaced time-delays would become a reality. Methods and concepts to analyze these data were initially developed using synchrotron TRX data [42-44], and could be also applied to XFEL data as shown previously [5]. However, on the ultrafast time-scale an interpretation by conventional, thermal bath-driven chemical kinetics as described in textbooks [45] is not applicable. Reactions proceed on excited-state potential energy surfaces (ES-PES) and are driven by electrostatic interactions [46]. Transitions to the ground-state potential energy surface (GS-PES) may occur through conical intersections [46]. The description of the dynamics on the ultrafast time scale as well as the characterization of functional modes and structures near the conical intersection now is an important goal of TRX. In this review, TRX experiments using low-repetition-rate XFEL sources are covered. They, for the first time, allow insight into biomolecular reactions with versatility and speed that has been impossible before.

\section{Reaction Initiation}

Despite the larger protein consumption, macromolecular reactions can be investigated with time-resolved serial crystallography (TR-SX) at the synchrotron [47] or with TR-SFX at the XFEL [4]. In fact, the serial crystallography approach seems to be predestined for these applications. When a reaction is started in the microcrystals upstream of the X-ray interrogation zone (see Figure 1), a time-resolved dataset is collected without additional complications. The challenge is to provide a versatile system to start reactions in crystals. This is most straightforward when the reaction can be initiated by light in and near the visible range. This requires (i) the presence of a light-sensitive compound, a chromophore, and (ii) that absorption of light is functional and triggers a biologically meaningful reaction. Examples are provided further below. The chromophore is activated by an 
intense, short or ultrashort optical laser flash, which generates a response of the biomolecule on various time scales. The laser flash is synchronized to the accelerator radio frequency of the pulsed X-ray source. This way, the time delay $\Delta$ t between laser and X-ray pulses (Figure 1) can be selected and adjusted. When time delays are substantially shorter than the 100-ps pulse duration of the synchrotron, XFELs are required. A complication arises caused by the substantial temporal jitter of the XFEL beam which is around $300 \mathrm{fs}$ [48]. If the biological reaction is to be observed on the femtosecond time scale, the temporal differences between laser and X-ray pulses must be measured on a shot-by-shot basis using a timing tool $[5,6,49,50]$. This enhances the time resolution substantially beyond the jitter. Another, more general method to trigger reactions in light-insensitive biomolecules and enzymes is described later on. The result of a successful TRX experiment is one or more complete datasets of reflection intensities collected after light activation and a complete reference dataset collected in the dark (Figure 1).

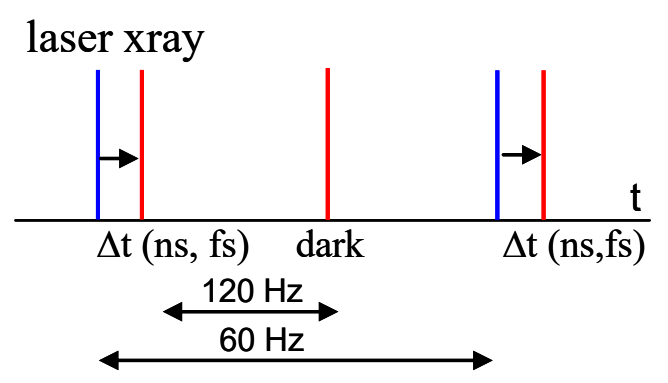

Figure 1. A time-resolved macromolecular crystallography (TRX) experiment with the pump-probe method. The pump laser pulse (blue bar) starts the reaction, and the ultrashort X-ray pulse (red bar) probes the progress of the reaction after a time delay, $\Delta$ t. Here, $X$-ray data collection in the dark as the reference is interleaved with data collection after laser light activation. The $\mathrm{X}$-ray data collection rate is $120 \mathrm{~Hz}$, as available at the LCLS, and the laser repetition rate is $60 \mathrm{~Hz}$ in this example.

\section{Data Collection and Structure Determination}

During X-ray exposure, a crystal diffraction pattern is collected by the detector. Commercially available detectors installed at synchrotrons output a file format that typically consists of a header that includes information such as pixel size, pixel numbers in $\mathrm{x}$ and $\mathrm{y}$ dimensions, detector distance from the crystal, beam center, etc., followed by the raw data as a byte stream. Data analysis follows established procedure [16,51]. Detectors available at XFELs such as the CSPAD [52] or the AGIPD [35] stream the content of multiple active detector panels individually. This information needs to be gathered and stored in a user-accessible form. In addition to the detector image, additional information is collected, such as the spectral traces of the timing tool to determine the relative laser pulse to X-ray pulse delays $[49,50,53]$. All the data are concentrated on a per-event (exposure) basis in files based on the hierarchical data format (HDF). Diffraction patterns containing Bragg reflections are identified in the stream of detector data using a hit-finder such as the popular Cheetah software [22]. Since the diffraction patterns arise from microcrystals in random orientation, each pattern needs to be indexed anew, after which the highly partial reflection intensity can be extracted. This requires specialized software, such as CrystFEL $[23,54]$, designed to index and analyze still exposures. After averaging a large number of observations for each reflection, a complete dataset covering $3 \mathrm{D}$ reciprocal space is obtained. This method of data processing has been named, based on the random nature of the crystal orientation, Monte-Carlo integration [11].

\subsection{Twinning}

With the serial approach, a complete dataset generated is composed of observations from a large number of different crystallites. This leads to an additional complication: In some space groups, some of the cell axes are identical in lengths. The indexing algorithm assigns cell axes randomly from 
crystallite to crystallite. A consistent indexing convention cannot be maintained. This may lead to an indexing ambiguity. Even when the cell axis lengths are not identical, such as in monoclinic space groups, some of the axes can have almost the same lengths, or there may a diagonal that by chance is of similar length compared to another cell axis. An example is sperm whale myoglobin crystallized in space group P2 1 with room temperature unit cell parameters $a=64.5 \AA, b=30.9 \AA$, and $c=34.8 \AA$, $\beta=105.8^{\circ}$. The short diagonal $\mathrm{d}$ of the parallelepiped spanned by a and $\mathrm{c}$ is $64.4 \AA$ : essentially the length of a. Also, the angle between the diagonal $\mathrm{d}$ and cell constant $\mathrm{c}$ is $105.6^{\circ}$, which is essentially $\beta$. Accordingly, when indexing, either the true cell constant or the diagonal will be randomly assigned to be cell constant a. As should be obvious, the intensities of reflections with like indices in the same pattern indexed with either one or the other indexing convention do not match. This twofold indexing ambiguity can be resolved by correlating intensities of reflections with like indices in two patterns and altering the indices in one of the patterns when the correlation is low [55]. For the above example of myoglobin, the operator $\mathrm{h}+\mathrm{l},-\mathrm{k},-1$ needs to be applied (see also [6]). It should be mentioned that the indexing ambiguity for myoglobin cannot result in a merohedrically twinned macroscopic crystal. For this to occur, the ambiguous cell axes must be exact. An example is space group $\mathrm{P}_{3}$, where axes $a$ and $b$ have exactly the same length [4]. There exists the indexing ambiguity $h, k, l$ and $\mathrm{k}, \mathrm{h}, \mathrm{l}$ (minus signs are not necessary in $\mathrm{P}_{3}$ due to symmetry). Under these conditions, (merohedrally) twinned macroscopic crystals might also exist [56]. In other, hopefully rare cases, the inability to distinguish cell axes with almost the same lengths might generate severe problems, especially at low resolution, with highly mosaic crystals containing big macromolecular complexes. Software to process SFX data therefore needs to provide a reliable mechanism to solve the indexing ambiguity (see [55] and http://www.desy.de/ \{\}twhite/crystfel/manual-ambigator.html).

\subsection{Difference Maps}

When the indexing ambiguity is solved and the partial intensities are scaled and merged, the integrated intensities can be converted to amplitudes with standard methods [57]. A reference dataset, $F(r e f)$, and a time-resolved dataset, $F(t)$, are obtained this way. It is imperative to scale the time-resolved amplitudes as accurately as possible to the dark (reference) amplitudes. The program 'scaleit' available within the CCP4 suite of programs [57] is particularly useful [4]. Difference amplitudes $\Delta F=F(t)-F($ ref $)$ are then determined. If the unit cell parameters do not change, isomorphous difference maps are calculated from the $\Delta F$ and phases from the reference model. Atomic displacements caused by structural changes are identified by pairs of positive and negative difference electron density features. Valid negative features are always on top of atoms of the reference structure. Chemically meaningful positive features must be interpreted with a new structure. To find this (unknown) structure can be difficult, since positive difference electron density features and negative features tend to cancel out. In addition, population transfer from the resting state into the reaction is usually quite small: on the order of 5-20\% [58]. Especially when the structural changes are small, the void between the features is confusing, and the atoms tend to be shifted too much towards the positive features. Fortunately, there exists a way to produce a conventional map where the population transfer is extrapolated to $100 \%$ [59]. A factor $N$ of the measured difference, $\Delta F(o b s)$, is added to calculated structure factors, $F($ calc $)$, determined from the reference state model to obtain extrapolated structure factors, $F($ ext $)=N \cdot \Delta F($ obs $)+F($ calc $)$, from which a conventional map can be calculated. When a larger fraction of molecules has been activated in the crystal, $N$ is small: on the order of 2-5 [4]. Even when the fractional concentration of activated molecules (FCM) is small, this method is successful. Then, however, $N$ is large [60]. The resulting extrapolated map is noisy due to errors caused by the difference Fourier approximation [61] and due to experimental noise in the (then) small difference amplitudes. $N$ can be estimated ( $\mathrm{N}_{\text {est }}$ ) even in the presence of low FCM by subsequently adding more of the $\Delta F$ to the dark structure factors and inspecting the resulting extrapolated map at positions where there is strong negative difference density in the difference map. This can be conveniently done by carving out a spherical volume from the extrapolated map positioned at locations that display 
strong difference electron density. The negative (extrapolated) density found within the spherical volume is summed up below a threshold $[43,60]$, and the result $\left(\Sigma_{\mathrm{S}}\right)$ is plotted as a function of $\mathrm{N}$. The appropriate $\mathrm{N}_{\text {est }}$ is found at the point where $\Sigma_{\mathrm{s}}$ starts to diverge [62]. Molecular model $(\mathrm{s})\left(\mathrm{M}_{\mathrm{int}}\right)$ can be found which interpret the extrapolated electron density. $\mathrm{M}_{\mathrm{int}}$ is fit into the extrapolated map by a real space refinement in an appropriate program, such as coot [63], and conventionally refined against the extrapolated amplitudes. In the case of high $N_{\text {est }}$ values, quality factors $\left(R_{\text {cryst }} / R_{\text {free }}\right)$ obtained after the refinement are poor. Nevertheless, a valid $\mathrm{M}_{\text {int }}$ is obtained that can be tested against the observed difference data. For this, structure factors are calculated, each from the refined $\mathrm{M}_{\mathrm{int}}$ and the reference structure. From these, difference structure factors are obtained from which a calculated difference map is computed. The calculated difference map can then be compared to the observed difference map. The agreement between the observed and calculated difference maps is inspected, for example, by using an appropriate correlation coefficient, and may be optimized by repeating the analysis with slightly varying factors $\mathrm{N}_{\text {est }}$ and/or different models. Once the best $\mathrm{M}_{\mathrm{int}}$ is found, phases for the $\Delta \mathrm{F}$ are available $[43,60]$ and phased extrapolated structure factors can be determined. A refinement against the phased extrapolated amplitudes usually results in acceptable $\mathrm{R}$ factors $[4,5,43,58,60]$. However, the quality of $\mathrm{M}_{\mathrm{int}}$ should be primarily based on the similarity (the correlation) between the calculated difference map and the observed difference map. Ideally, $\mathrm{M}_{\mathrm{int}}$ explains all difference features, and even spurious (positive) difference electron density values are interpreted correctly. This is even more important when the FCM is small and, correspondingly, $\mathrm{N}_{\text {est }}$ is large.

When the unit cell parameter changes substantially during the reaction, isomorphous difference maps cannot be calculated. Then, 'omit' difference maps must be calculated using data obtained after reaction initiation only (see, e.g., [64]). For this, a structural model with the region of interest removed (omitted) is refined against the light data, preferentially with simulated annealing to minimize phase bias. Structure factors $F($ omit $)$ are calculated from the model. The omit difference map is then calculated from the amplitudes $\Delta F=F(t)-F$ (omit), and phases from the refined (omit) model. Extrapolated structure factors, $F(e x t)$, as well as extrapolated maps to guide structural interpretation, may also be calculated if needed: $F($ ext $)=F($ omit $)+N \cdot[F(t)-F($ omit $)]$.

\subsection{Analysis of Time Series}

The ultimate goal of time-resolved crystallography is the determination of the dynamics of the crystalline ensemble from the beginning to the end of a reaction. Chemical kinetics is governed by rate coefficients and chemical kinetic mechanisms that need to be extracted from a comprehensive time series of X-ray data. Approaches based on a component analysis, specifically on the singular value decomposition (SVD), have been developed [42] and successfully applied to synchrotron [58,65-69] and XFEL [5] data. Most importantly, mixtures that inevitably occur during chemical kinetics are separated into pure constituents. For more details, the reader is referred to specialized reviews $[43,44,70]$. The SVD-based analysis then provides a comprehensive view of the reaction. A compatible chemical kinetic mechanism, the rate coefficients of this mechanism, and the time-dependent concentrations of the intermediate states as well as the time-independent structures of the intermediate states that are populated during the reaction [43] can be determined. Even barriers of activation may be extracted purely from the time-resolved X-ray data [58]. On ultrafast time scales, the description according to chemical kinetics breaks down. Rather than driven by the heat bath, the dynamics is governed by electrostatic interactions on the excited- and ground-state potential energy surfaces (see below). The crystalline ensemble moves in synchrony, since the individual molecules do not have the time to kinetically dephase. Protein quakes $[71,72]$ and collective motions $[5,6]$ become observable. Closely spaced time delays are required on these time scales, and new analysis methods must be developed [73]. 


\section{The Blue-Light Receptor Photoactive Yellow Protein}

Ever since its discovery [74], the photoactive yellow protein (PYP) was used to motivate innovations in TRX. Numerous publications in high-ranking journals testify to the importance of this small protein $[4,5,59,67,75-77]$. By absorbing at a wavelength of $460 \mathrm{~nm}$ (in the blue region), it senses blue light and it is thought to be responsible for the negative phototaxis [78] of the bacterium (Halorhodospira halophila) in which it was originally identified. The central chromophore in PYP is photoactive. It isomerizes from trans to cis configuration [79], which initiates conformational changes of the protein. After the chromophore isomerization, PYP transitions through a photocycle with several intermediates that acquire subsequent global, but distinct, conformations. Synchrotron-based TR crystallography elucidated the photocycle to almost completion $[58,65,67,69,77]$. However, the trans-to-cis photoreaction remained obscure because it is much faster than the pulse duration of X-ray pulses available at synchrotrons. As one of the earliest experiments at the LCLS, an experiment to probe this initial reaction of the PYP photocycle was conducted with macroscopically large $(40-\mu \mathrm{m}$ diameter, $\sim 1$-mm long) crystals (Figure 2). This experiment did not produce datasets of sufficient quality to obtain a time-resolved signal [80]. An international consortium of researchers tackled the problem successfully with microcrystals at the CXI instrument of the LCLS [4]. They produced, for the first time for any biological macromolecule, a time-resolved difference electron density (DED) map at the XFEL. The quality of the DED was unprecedented and fully unexpected. At a 1- $\mu$ s time delay, the DED map showed difference features on the order of 20 times above the noise, which had never observed for PYP at synchrotrons. This experiment then opened the door wide to advance to the femtosecond time range. An experiment with fs time resolution was conducted again at the CXI instrument; this time, however, with the reaction initiated by a femtosecond laser [5]. For the first time, the chemically all- important trans-to-cis isomerization was seen in real time by observing how electron density clouds shift (Figure 3). Quantum mechanical molecular dynamics simulations show that after light absorption, the PYP is lifted to the electronic excited-state potential energy surface (ES-PES). However, the chromophore configuration is still trans on the ES-PES (Figure 3a). The experiment showed, for the first time, macromolecular relaxations on an ES-PES. All other TR-crystallographic experiments to this date featured PYP on the electronic ground state (GS)-PES, where the reaction is driven by the thermal bath. The trans-to-cis isomerization happens at about $600 \mathrm{fs}$ at the seam between the ES-PES and the GS-PES: the so-called conical intersection. The transition through the conical intersection, as well as the initial relaxation on the GS-PES, was also time-resolved in this experiment. In contrast to conventional chemical kinetics, which is governed by rate coefficients and temperature, the ultrafast relaxations on ES-PES and GS-PES are likely not temperature-dependent. The relaxations are driven by electronic interactions and related structural relaxations after instantaneously accessing the ES-PES. After the transition through the conical intersection, electronic relaxations commence on the GS-PES. The initial events are governed by extreme acceleration of chromophore atoms on the order of $10^{14} \mathrm{~m} / \mathrm{s}^{2}$. Some of the chromophore atoms reach the speed of sound after $100 \mathrm{fs}$ and collide with the rigid (on this time scale) protein matrix [5]. Most likely, there exist functional modes in the protein which might be excited by this collision. They may facilitate a swift rotation about the chromophore tail's double bond (Figure 3a) and enhance population transfer into the photocycle. The characteristic time of the relaxation through the conical intersection ( $\sim 60 \mathrm{fs})$ and the relatively high primary yield (20\%) for photocycle excitation [81] are testimony for this. Eight hundred femtoseconds after excitation, the chromophore is in a very twisted near-cis configuration, which relaxes further. The structure at the 3 -ps time delay (Figure $3 b$ ) is already very similar to the synchrotron-derived structures 100 ps after photon absorption $[67,77]$. The PYP will continue to drive new experiments and support new ideas. For example, laser pulse shaping techniques $[81,82]$ might be able to control molecules on the ES-PES and steer the transition into the photocycle. High-repetition-rate XFELs are required to collect the necessary X-ray data, which should cover closely spaced time delays in high-dimensional parameter space. New attosecond-pulsed $X$-ray sources will explore, time-resolve, and remove the notion of instantaneousness from the chromophore excitation itself. 


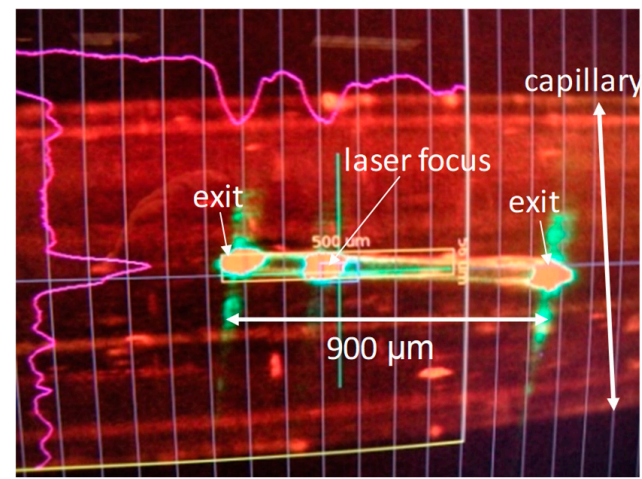

Figure 2. Screenshot of a photoactive yellow protein (PYP) crystal (pale yellow) displayed on a monitor at the XPP instrument of the LCLS during laser illumination. The crystal of size $900 \times 40 \times 40 \mu \mathrm{m}^{3}$ is kept in a glass capillary. It is illuminated by a femtosecond laser pulse (laser focus). The crystal apparently acts as a waveguide, with the laser light exiting at both ends.

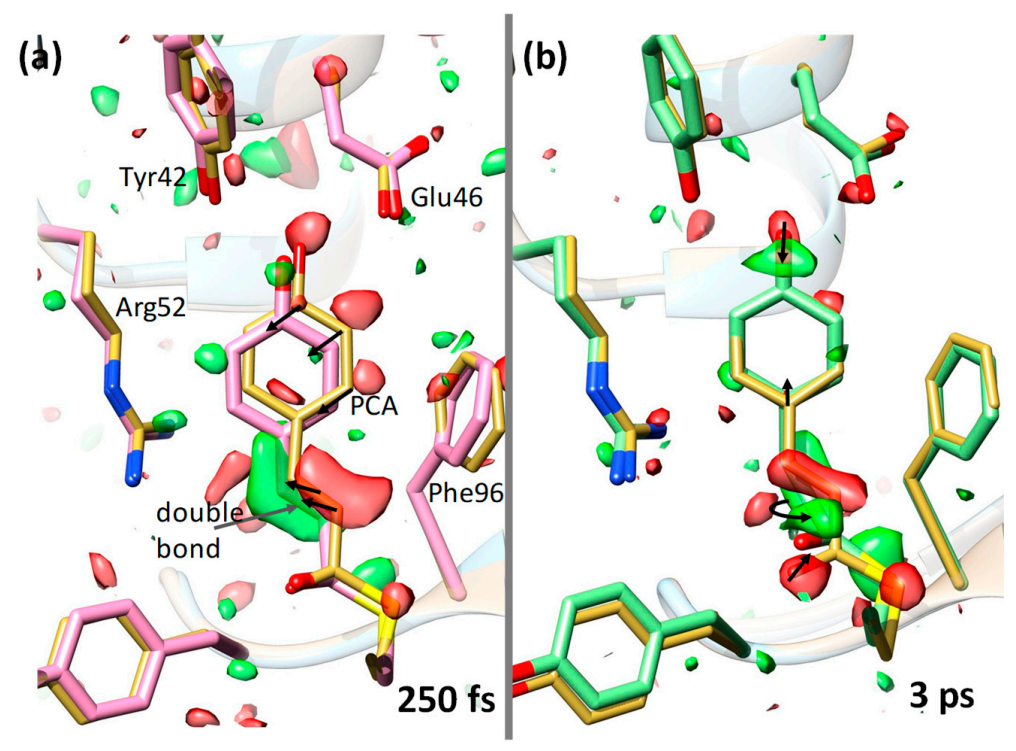

Figure 3. Ultrafast structural changes in the chromophore pocket of PYP [5] Green represents a positive difference electron density and red a negative difference electron density (on the 3/-3 $\sigma$ contour level). Yellow structure represents a reference (dark state) structure. The p-coumaric acid (PCA) chromophore as well as some nearby residues are marked. (a) $250 \mathrm{fs}$ after laser excitation (pink structure); the chromophore configuration is still trans. Larger structural changes are denoted by arrows. (b) 3 ps after laser excitation (green structure); the structure is cis. Isomerization occurred about the double bond (curved arrow) at the chromophore tail. Some structural changes are also shown by arrows.

\section{Transition Metal-Containing Proteins}

Myoglobin $(\mathrm{Mb})$ is a paradigm of a biological macromolecule for biophysicists. It is sufficiently complex, yet small enough to reveal important properties of proteins under controlled conditions. $\mathrm{Mb}$ contains a central pigment called heme, which is a protoporphyrin (IX) molecule that coordinates to a single iron atom (Figure 4). If carbon monoxide (CO) is added to $\mathrm{Mb}$, it binds to the iron, forming $\mathrm{Mb}-\mathrm{CO}$. Once the $\mathrm{CO}$ is flushed away from $\mathrm{Mb}$, early protein relaxations and those related to subsequent geminate rebinding can be observed with time-resolved methods. Ligand migration and protein conformational substates were all discovered with the help of this molecule [66,83-88]. Figure 4 shows results from an earlier TR crystallographic study on the L29W mutant of Mb [66]. Already within $1 \mathrm{~ns}$ after the $\mathrm{CO}$ is flashed away, substantial protein relaxation has occurred, the distal histidine has swung into the heme plane, the CO has migrated away from the heme, and the heme 
itself is substantially domed with the heme-iron displaced out of the heme plane. The earliest phases of this reaction were then investigated on femtosecond time scales at the XFEL [6]. The trajectory of the $\mathrm{CO}$ to its initial docking site could be revealed, as well as initial protein relaxations, extending and confirming earlier results from synchrotron-based TR Laue crystallography $[66,85,87,88]$ and providing a solid structural base for ultrafast spectroscopic findings [89,90].

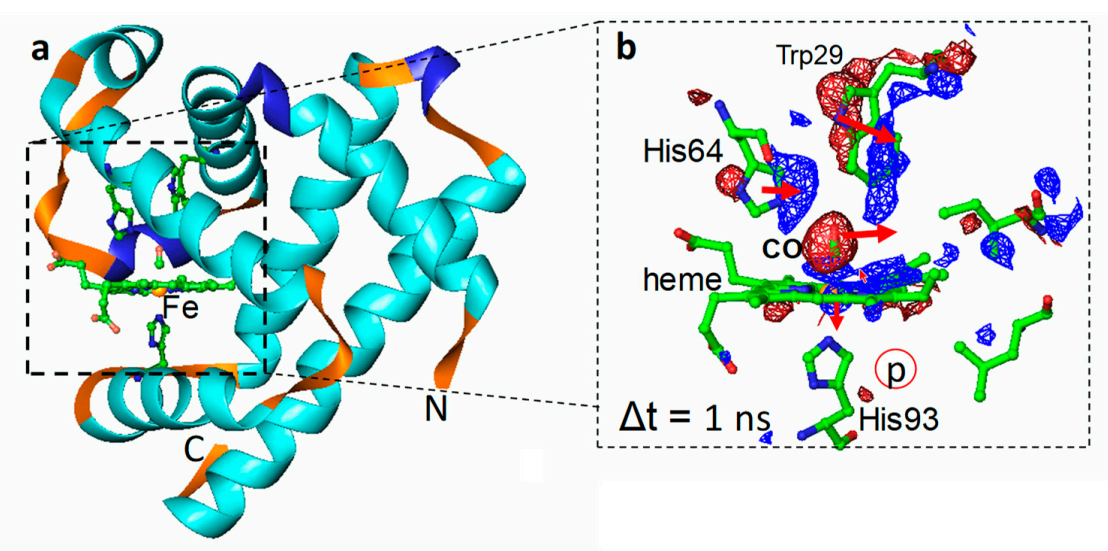

Figure 4. Time-resolved crystallographic photoflash experiment on the L29W mutant of Mb-CO [66]. (a) Overall structure of $\mathrm{Mb}^{\mathrm{L} 29 \mathrm{~W}}-\mathrm{CO}$ in the dark. Dashed box: heme pocket. Some important residues are displayed. The heme iron is shown as a yellow sphere. (b) Close-up of the heme pocket $1 \mathrm{~ns}$ after an intense optical laser flash to start photodissociation of the $\mathrm{CO}$ from the heme. $\mathrm{t}$. The heme and important residues are marked. Red: negative difference electron density; blue: positive difference electron density $(-/+3 \sigma$ contour levels, respectively). Red arrows show structural relaxations at this time delay. In this mutant, the Trp29 transiently occludes the primary docking site of the CO. CO is found at time delays $>1 \mu$ s on the proximal side of the heme (red-circled $p$ ).

Transition metals are ubiquitous in biology. Iron is probably most abundant, but other metals such as copper and manganese are also found in important proteins and enzymes. Examples include the heme-containing cytochrome-c nitrite reductase [91,92], the manganese- and iron-containing photosystem II [33,93,94], the terminal oxidase in the respiratory chain (copper and iron) [95], as well as various superoxide dismutases (with iron, manganese, copper, or other metals in their active sites) $[96,97]$. There are many more metalloproteins [98]. Most of them catalyze reactions of biologically and biomedically high importance, which merits investigation of their catalytic mechanism. Care has to be taken that the transition metal is not photoreduced during X-ray structure analysis [99]. Otherwise, the change of the oxidation state might lead to rapid structural changes that may be significant, even during the ultrafast fs X-ray pulses at XFELs [19,100]. Although the diffraction-before-destruction principle [17] suggests that atomic displacements caused by radiation damage can be neglected, there exist cases, such as in photosystem II, where rapid configurational changes could affect the interpretation of catalytic mechanisms [33,101-103]. In other cases, where conformational changes are large, small effects due to radiation damage might play a smaller role. In TR-SFX, the crystal is discarded after each X-ray pulse and the next crystal is new and pristine. As a result, a reaction initiated in these crystals is completely unaffected by radiation damage until it is probed. This is in contrast to the synchrotron, where radiation damage of a crystal by multiple X-ray pulses (or by a longer X-ray pulse) might also impair the kinetics [62]. However, also at the synchrotron, the feasibility of serial macromolecular crystallography has been shown with monochromatic and pink beams $[47,104-106]$. Such an approach would also provide a clean, essentially X-ray-damage-free description of the progress of a macromolecular reaction. Still, the initiation of reactions in crystals, especially in enzyme crystals, remains a challenge. Methods to start reactions by laser pulses are fairly established, but most proteins and especially enzymes are not light-sensitive. Even if they contain a light-sensitive cofactor, its illumination with light would likely not be functional and would not trigger 
an enzymatic reaction. Apart from inactive caged substrates that could be soaked into enzyme crystals and activated by laser pulses [107-109], there are only a few examples where light absorption actually may be used to control enzymatic activity. Some such examples are mentioned below. Other examples include enzymes that are engineered to be coupled to light-sensitive domains or moieties whose light activation would change the enzymatic activity $[110,111]$.

\section{Enzymes}

Enzymes are biocatalysts; they perpetuate the catalytic functions of life, and thus, they must work properly and their functions must be regulated. If their functions are compromised, severe diseases may result. Enzymatic reactions decide the fate of an organism. Cancer, for example, often results from out-of-control enzymatic function, as comprehensively described in textbooks [112]. On the other hand, pathogens causing infectious diseases can be destroyed by targeting their essential enzymes. Hence, it is of utmost importance to investigate enzymatic activity, understand catalytic mechanisms, and explore opportunities to control their function. The "holy grail" of TRX is therefore the ability to investigate reactions and interactions of enzymes with their specific substrates in real time. At synchrotrons, these experiments are complex because a number of $\mathrm{X}$-ray exposures (detector readouts) from a single macroscopic crystal are usually required to produce a complete dataset. This may require flow cells or other means $[113,114]$ to load the crystal with substrate and remove product after each exposure. To initiate the enzymatic reaction in the crystals, inactive, caged substrates may be required that first need to diffuse into the crystals, and are subsequently activated by laser pulses [107]. Crystals of many proteins, especially biomedically important ones, tend to scatter weakly and exhibit large mosaicities. Both may impair the quality of the (monochromatic and especially Laue) diffraction patterns collected at synchrotrons. Despite these demanding requirements, a number of studies have been successfully conducted $[3,16,115,116]$. However, a transformative step forward would be the elimination of experimental difficulties to the point such that routine investigations become generally feasible on all sorts of biomacromolecular reactions. Serial crystallography with microcrystals offers a practicable approach. Since the crystals are so small, they can be mixed with substrate quickly and exposed one-by-one to the X-ray beam at a time $\Delta \mathrm{t}$ after mixing. No flow cells are required this way. A successful application of this approach has been demonstrated recently [64] and is described below.

The first enzyme structure to be solved was that of lysozyme in 1965 [117]. Lysozyme catalyzes the hydrolytic separation of 1,4-beta-links between $\mathrm{N}$-acetylmuramic acid and $\mathrm{N}$-acetyl-D-glucosamine of bacterial cell walls; hence, it has antimicrobial activity. In chicken egg whites and human nose mucus, lysozyme is the first line of defense against bacterial infections. Ever since, researchers have been wondering how this enzyme performs its catalytic function. The static structure reveals clues, such as the structure of the catalytic cleft and the positions of catalytically important amino acid residues. However, as the $\mathrm{X}$-ray structure is static, the precise catalytic mechanism is difficult to determine. Even more important than lysozyme in the fight against infectious diseases are the so-called penicillin-binding proteins (Figure 5a). These enzymes catalyze the linkage of $\mathrm{N}$-acetylmuramic acid to $N$-acetyl-D-glucosamine to form the cell wall in the bacteria, a reaction just opposite to the lysozyme reaction. $\beta$-lactam antibiotics such as penicillins and chemically similar compounds such as the cephalosporins irreversibly inhibit the penicillin-binding protein [118]. Once blocked by these compounds, the enzyme is not able to maintain the integrity of the cell wall and the bacteria perish. Unfortunately, resistance against antibiotics is rampant. $\beta$-lactamases are found among a disturbingly large number of possible resistance mechanisms [119-121]. These enzymes modify penicillin and related compounds by opening the peculiar, relatively unstable $\beta$-lactam ring of these compounds. Some $\beta$-lactamases are strikingly similar to the catalytic domain of the penicillin-binding proteins (Figure 5a). Even the catalytic clefts are essentially identical (Figure 5b). In contrast to the penicillin-binding protein, which is irreversibly and covalently modified by the antibiotic, the $\beta$-lactamases bind the antibiotic, catalyze the ring opening, and are finally able to hydrolyze and release 
the modified product. The free enzyme can now engage in a subsequent cycle of antibiotic modification, eventually rendering the entire amount of administered antibiotics ineffective. The catalytic cycle of a typical $\beta$-lactamase lasts on the order of $1 \mathrm{~s}$, with several intermediates persisting on the millisecond time scale [122]. The enzyme substrate complex forms within ten ms, after which an active-site amino acid residue attacks the lactam ring, opens it, and covalently binds the reaction product. The Mycobacterium tuberculosis $\beta$-lactamase (BlaC), an Ambler class-A $\beta$-lactamase [123], has been investigated recently at the XFEL $[64,124]$. Experiments on this $\beta$-lactamase was driven by three important considerations: (i) BlaC is biologically and biomedically highly significant. Hence, results are widely important. This justifies the use of limited beamtime at the XFEL. (ii) The reaction catalyzed by BlaC is simple enough that the enzyme can be used as a model system to establish structure-based enzymology at the XFEL. (iii) BlaC forms well-diffracting microcrystals, and $\beta$-lactam antibiotics are readily available and very soluble in most cases. The approach to investigate the $\mathrm{BlaC}$ reaction has been named 'mix-and-inject' serial crystallography (MISC) [124]. In MISC, micron-sized enzyme crystals are mixed with substrate before the mixture is injected into the $\mathrm{X}$-ray interaction volume. The substrate diffuses into the crystals and initiates a reaction. Since the crystals are so small, diffusion times are fast; much shorter than the time required for one catalytic turnover. If the $\mathrm{BlaC}$ reaction can be followed, this approach will also work with other important enzymes.

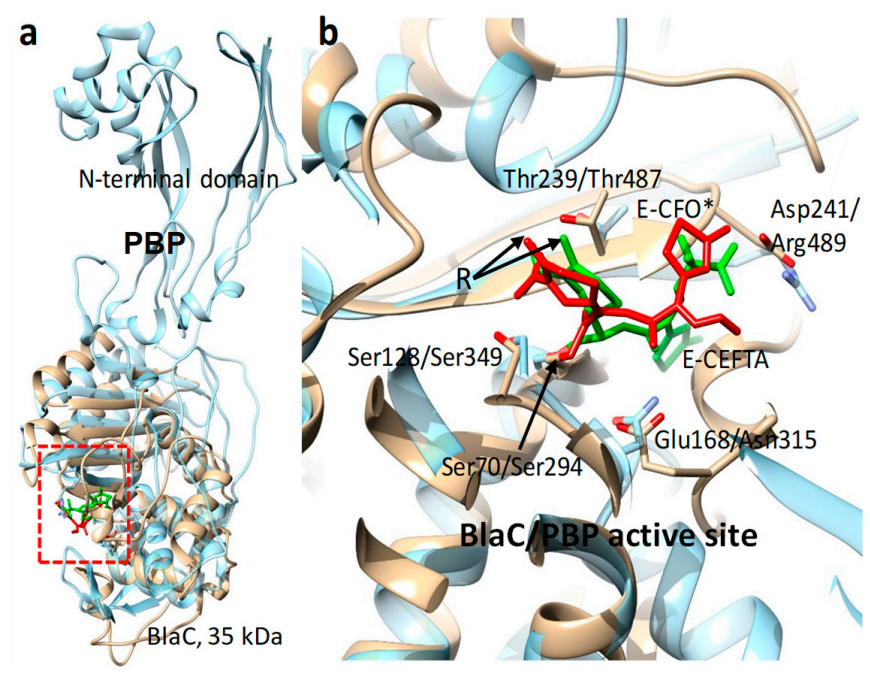

Figure 5. Structural comparison of penicillin-binding protein (PBP, blue, PDB entry $3 \mathrm{OCN}$ ) and M. tuberculosis $\beta$-lactamase (BlaC; brown, PDB entry 6B69). (a) Overall view: BlaC is structurally very similar to the $\mathrm{C}$-terminal domain of the PBP. (b) Detailed view of the active sites with essential amino acids in BlaC/PBP shown according to numbering convention. The cephalosporin antibiotics ceftriaxone $\left(\mathrm{CFO}^{*}\right.$, red) and ceftazidime (CEFTA, green) are bound to serine residues (arrow) in the active sites of BlaC and PBP, respectively. The leaving group of the cephalosporins ( $R$, arrows) is cleaved off.

Diffusion is based on Fick's laws, the second of which is:

$$
D \nabla^{2} C=\frac{\partial}{\partial t} C
$$

where $D$ is the diffusion coefficient, $\nabla^{2}$ is the Laplace operator, and $C$ is the time- and space-dependent concentration of substrate in the crystals, which is initially zero. This partial, second-order differential equation can be solved subject to certain boundary conditions [125]. Diffusion times to the center of the crystal can be estimated this way. They approach $1 \mathrm{~ms}$ for crystals of about 1-5 $\mu \mathrm{m}$ edge lengths, depending on the substrate. In addition, Fick's first law relates the flux ( $\vec{J}$, the velocity with which the substrate enters the crystal) to the concentration gradient: $\vec{J}=-D \vec{\nabla} C$, with $\vec{\nabla}$ being 
the 'nabla' operator. Hence, the larger the substrate concentration outside the crystal, the higher the flux into the crystal, and the faster appropriate concentrations accumulate in the crystals. To reach proper occupancy of the enzyme-substrate complex, the number of substrate molecules should at least match the number of catalytic centers in the unit cell. This is called stoichiometric concentration. According to Fick's first law (and also evident from the solutions to Fick's second law), given properly high initial outside substrate concentrations, stoichiometric concentrations may be reached about an order of magnitude faster than the characteristic diffusion time, even faster than the mixing time (Table 1). Accordingly, the experiment's best time resolution is reached if the substrate is mixed with enzyme microcrystals rapidly, the initial substrate concentration is high, and crystals are as small as possible. Sub-ms time resolution is possible. These requirements led to the development of optimized 'mix-and-inject' injector devices $[64,126]$, where mixing is achieved efficiently to reach the required time resolution. Table 1 lists relevant parameters for a 30-ms time delay after mixing BlaC microcrystals with the cephalosporin antibiotic ceftriaxone (CEF) as substrate. Mixing plus characteristic diffusion times are on the order of $8 \mathrm{~ms}$, and stoichiometric concentration is reached even within the mixing time (5 ms). This is more than sufficient to time-resolve the initial 30-ms time delay.

Table 1. Time scales and other parameters important for consideration in a mix-and-inject experiment aimed to investigate an enzymatic reaction at a time delay of $30 \mathrm{~ms}$ after mixing.

\begin{tabular}{ccccccc}
\hline Delay & $\begin{array}{c}\text { Mixing } \\
\text { Time }\end{array}$ & $\begin{array}{c}\text { Crystal Size } \\
\left(\boldsymbol{\mu \mathbf { m } ^ { 3 } )}\right.\end{array}$ & $\begin{array}{c}\text { Diffusion Coefficient } \\
\left(\mathbf{c m}^{2} \cdot \mathbf{s}^{-\mathbf{1}}\right)\end{array}$ & $\begin{array}{c}\text { Diffusion } \\
\text { Time }\end{array}$ & $\begin{array}{c}\text { Substrate } \\
\text { after Mixing }\end{array}$ & $\begin{array}{c}\text { Time to Reach Stoichiometric } \\
\text { Concentration }\end{array}$ \\
\hline $30 \mathrm{~ms}$ & $5 \mathrm{~ms}$ & $10 \times 10 \times 3$ & $2.3 \times 10^{-6}$ & $3.5 \mathrm{~ms}$ & $240 \mathrm{mmol} / \mathrm{L}$ & $0.24 \mathrm{~ms}$ \\
\hline
\end{tabular}

The catalytic reaction of the $M$. tuberculosis BlaC with CEF has been observed from $30 \mathrm{~ms}$ to $2 \mathrm{~s}$ with MISC experiments performed at the LCLS $[64,124]$. CEF is already fully occupied in the catalytic cleft at $30 \mathrm{~ms}$ (Figure $6 \mathrm{~b}$ ). Next, the Ser-70 residue of the enzyme attacks the $\beta$-lactam ring (Figure $6 c, d$ ). This nucleophilic attack does not only open the ring, but also leads to the simultaneous release of a leaving group (R) from CEF. Very little evidence of this process is present at both $30 \mathrm{~ms}$ and $100 \mathrm{~ms}$. However, at $500 \mathrm{~ms}$, a covalent bond between CEF and Ser-70 has formed (Figure 6d). Since the leaving group's electron density is not well resolved due to high mobility, its ring electron density is a poor indicator of its presence (or release). The missing density on the sulfur atom of the leaving group, however, indicates that this group is split off. At $30 \mathrm{~ms}$ to $100 \mathrm{~ms}$, the structure of the enzyme-substrate complex, and at $500 \mathrm{~ms}$, the structure of the acyl complex can be determined. Two seconds after mixing, the situation is not that clear; apparently, the enzyme-substrate (ES) complex reappears (Figure 6e). The electron density looks similar to those for the 30-ms and 100-ms time delay. Since $2 \mathrm{~s}$ is a timepoint well in the steady state of the enzyme, one would expect that the most stable state, which should be the acyl complex, dominates the electron density. However, this is not the case, since the ES complex is observed at $2 \mathrm{~s}$. A more quantitative view is obtained when the coupled differential equations of the kinetic mechanism are integrated. The concentration profiles obtained can then be compared to the results from the MISC experiment. A compatible concentration profile can only be obtained when the rate of the nucleophilic attack reaction of Ser-70 onto the $\beta$-lactam ring is effectively blocked. Only then does the ES complex accumulate in the steady state. Although product inhibition has been known for cephalosporin substrates [127], this is the first time that such an inhibition has been proposed based on structural evidence, and may be useful for therapeutic applications. Additional experiments with closely spaced time points are necessary to determine the exact mechanism(s) of this inhibition. 


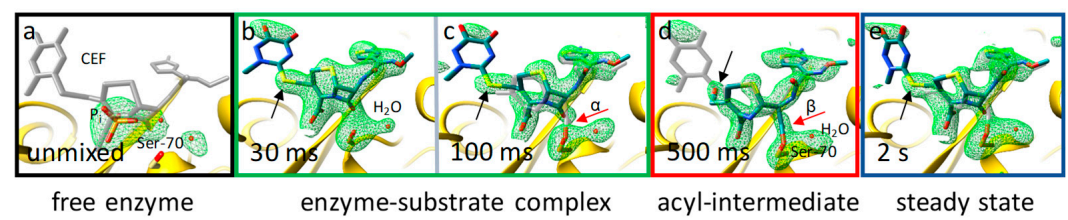

Figure 6. Active site structures during the BlaC reaction with CEF [64] as determined by MISC. Simulated annealing 'omit' difference density shown in green on the $2.5 \sigma$ level. (a) Catalytic cleft of the free enzyme, phosphate $\left(\mathrm{P}_{\mathrm{i}}\right)$, and water is present. Ser-70 is marked. The position of CEF is shown in gray as a guide to the eye. (b) Catalytic cleft $30 \mathrm{~ms}$ after mixing; resolution $2.75 \AA$. Strong electron density shows the CEF ligand. (c) Catalytic cleft $100 \mathrm{~ms}$ after mixing; resolution $2.15 \AA$. Gap in electron density (red arrow, $\alpha$ ) shows that the covalent bond has not yet formed. Black arrows in (b,c) point to the sulfur of the leaving group. (d) Catalytic cleft $500 \mathrm{~ms}$ after mixing; resolution $2.2 \AA$. The gap between the CEF and Ser-70 is closed, indicating a covalent bond (red arrow, $\beta$ ). The sulfur feature (black arrow, behind the hydroxyl) is gone. (e) Catalytic cleft in the steady state. Similarities to the 30-ms and 100-ms time delays are evident.

\section{Other Light-Controlled Proteins and Enzymes}

Membrane-bound receptors usually obtain catalytic activity when they are activated. The activity is triggered by the binding of an effector, such as a hormone, and transduced through the cell membrane to the cytoplasmic side. More downstream effectors bind to the receptor and are thereby activated. This leads to signal amplification that then causes changes in the cell behavior, such as growth and differentiation [112]. Light is also sensed by membrane-bound receptors which transmit the light signal into the cell. The most well-known of these is certainly the eye pigment rhodopsin $[128,129]$. Rhodopsins are seven-helix transmembrane proteins found in higher organisms as well as in bacteria, with diverse activities ranging from light perception to cation and anion transport [130]. The bacterial rhodopsin (bacteriorhodopsin, BR) found in halophilic purple bacteria [131] is likely the most investigated of them all. Upon light absorption, it pumps protons out of the bacterium, hence generating a proton gradient across the cell membrane. This proton gradient is used by another enzyme (ATP synthase) to produce the cell fuel ATP (adenosine triphosphate). This makes BR interesting for potential applications using sunlight to generate chemical energy. The central chromophore in BR is an all-trans retinal bound to a lysin, forming a general structure called a Schiff base. After absorption of green light $\left(\lambda_{\max }=520 \mathrm{~nm}\right)$, the retinal undergoes a trans-to-cis isomerization reaction that drives BR in a photocycle with multiple intermediates [132]. High-quality crystals of BR were obtained using a method developed by Landau and Rosenbush called lipidic cubic phase (LCP) crystallization [133-135]. Despite several decades-long successful structure determination studies of BR at synchrotrons, it has been difficult to investigate BR with the Laue method at room temperature. Crystals scatter weakly and are strongly radiation sensitive. This prevented TRX experiments on BR until the XFELs became available. Microcrystals of BR obtained through LCP crystallization can be extruded into the XFEL beam using the viscous matrix injector. Ultrafast time-resolved SFX investigations with the pump-probe technique become possible this way $[25,26]$. In BR, the $\Delta 13-14$ double bond near the Schiff base isomerizes on an ultrafast time scale. The Schiff base carbon moves substantially by about $2 \AA$ to accommodate the isomerization [136]. This then has a profound influence on the conformations of $\mathrm{BR}$ intermediates and the water network within the protein, and it provides a structural basis of how the BR performs its proton-pumping function $[26,136]$.

Absorption of light can regulate enzymatic activity in soluble proteins. The light is sensed in a photoactive moiety, and the signal is subsequently transferred to a domain with enzymatic activity. Ideally, the light sensor and the enzyme are located on the same protein. Such a photoresponsive enzyme was discovered in plants 80 years ago $[137,138]$ and was called phytochrome. Effects of phytochromes on plant morphology and physiology are numerous. Examples are etiolation, greening, shade avoidance, and leaf expansion [139]. Plant phytochromes are difficult to crystallize, especially in their full-length, enzymatically active, functional form. The discovery of homologous phytochromes 
(BphPs) in nonphotosynthetic bacteria has been a breakthrough $[140,141]$, since these BphPs tend to crystallize readily. Crystal structures are now known for BphPs of about a dozen bacteria [32,138], including structures of full-length BphPs [142,143] (see also Figure 7c) and a plant phytochrome B [144]. The phytochromes consist of four domains, three of which, called PAS, GAF, and PHY, form the photosensory core module (PCM), and the fourth is an effector domain with enzymatic activity (Figure $7 \mathrm{~b}, \mathrm{c}$ ). Red light is absorbed by the central chromophore, which for BphPs is usually biliverdin (BV) (Figure 7a). The chromophore undergoes a configurational change. The $\Delta 15-16$ double bond connecting rings $\mathrm{C}$ and $\mathrm{D}$ isomerizes from the Z-configuration (Figure 7a) to the E-configuration. This signal is picked up by a complex network of amino acid interactions $[32,145]$ and relayed towards the sensory tongue of the PHY domain (marked in Figure $7 \mathrm{~b}$ ). The sensory tongue completely changes its conformation from a $\beta$-sheet to an $\alpha$-helix $[146,147]$. In response, the PHY domain moves substantially (see arrows in Figure 7b), hence opening the PCM [146,147]. As the effector domain with enzymatic activity is linked to the PHY domain (Figure 7c), it must undergo large structural changes that are caused by the PHY domain displacements. The characterization of the signal transduction through the PCM towards the effector domain is subject to intense investigations. First, the chromophore isomerization must be structurally explored, and second, the signal transduction must be identified in real time by time-resolved experiments. Whether crystals will survive the large structural changes is a matter of debate. However, microcrystals used at XFELs seem to be surprisingly robust towards changes in the unit cell and tolerate even space group changes [148], so chances of being able to observe this important photoreaction are excellent. In addition to the significance of the phytochrome reaction for bacterial behavior and development [32], the identification of key amino acid residues in the mechanism of this isomerization would have biomedical applications. They guide the design of new fluorescent biomarkers in the far red [149] for deep tissue investigations [150], Förster resonance energy transfer (FRET) applications, or optical applications with super-resolution [151].
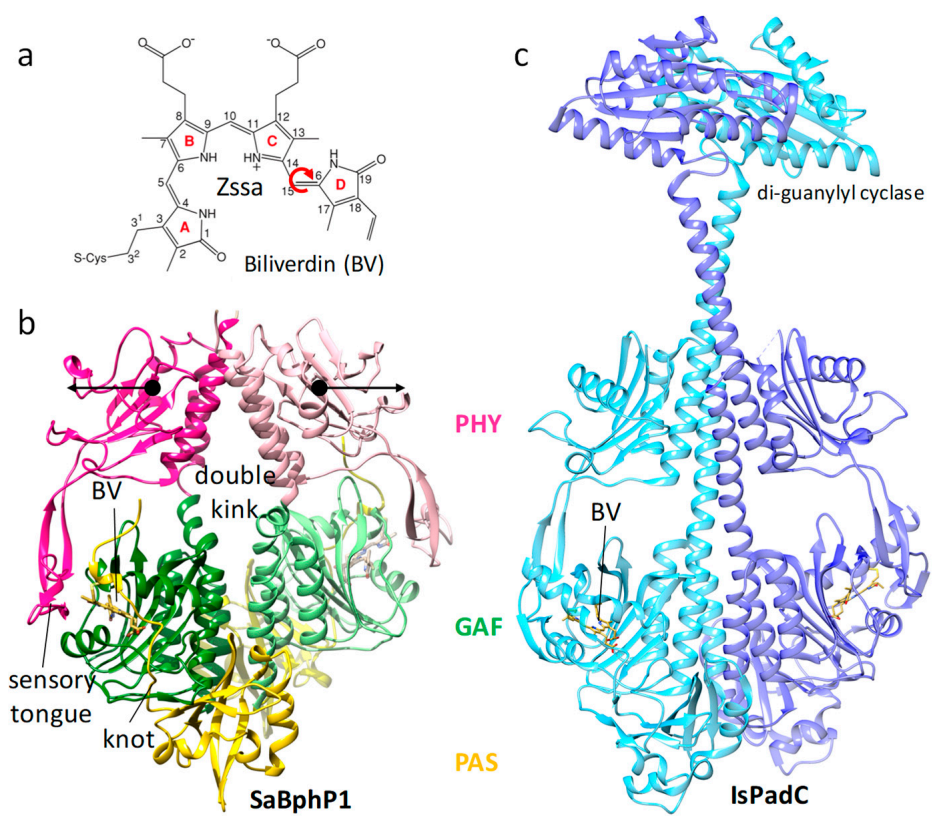

Figure 7. Bacterial phytochrome structures. (a) Structure of the central chromophore, biliverdin (BV). In dark-adapted BphPs, biliverdin (BV) is found in most cases in the Z syn-syn-anti configuration. Red arrow: isomerization upon red light absorption. (b) Structure of the myxobacterial phytochrome 1 (SaBphP1) photosensory core module; PDB entry 6BAO [32]. PAS, GAF, and PHY domains are colored yellow, green, and magenta, respectively. The sensory tongue, the knot, and the BV are marked. Black arrows: structural displacements of the PHY domains after light absorption; PDB entry 6BAO. (c) Structure of the full-length Idiomarina spp. phytochrome-activated diguanylyl cyclase (IsPadC), pdb entry 5LLW [142]. 


\section{Outlook}

The investigation of the catalytic functions of many soluble and membrane-bound biologically and biomedically highly significant enzymes with the mix-and-inject technique are at the frontier of macromolecular TR-SFX $[64,124,148]$. The structural characterization of electron transfer reactions in photosystem I (PSI) and photosystem II (PSII), as well as the water splitting catalyzed by the oxygen-evolving complex (OEC) in PSII, is ongoing, with spectacular results $[33,93,103]$. Proposals on numerous other light-sensitive proteins and enzymes await receiving beamtimes at the existing XFELs. Ligand binding to and signal transduction by membrane-bound receptors, such as the many G-protein coupled receptors [152] and other biologically highly significant receptors, await investigation. High-repetition-rate XFELs will reduce experimental times and keep protein consumption to a minimum. The way in which experiments will be conducted will become very different from today. Hundreds or even thousands of different microcrystalline samples can be examined in a few hours by specialized staff at most sophisticated high-repetition-rate XFELs. Accordingly, hundreds of comprehensive time series may be collected in one shift of XFEL beamtime using different substrates covering a vast parameter space. As a result, crystallo-kinetic information obtained by TR-SFX (or potentially time-resolved serial crystallography at synchrotrons) will become a potent tool in the fight against cancer and infectious diseases.

Funding: This work was supported by NSF STC-1231306 (BioXFEL).

Acknowledgments: M.S. thanks Emina Stojkovic (NEIU) and Peter Schwander (UWM) for reading and commenting on an earlier version of this manuscript.

Conflicts of Interest: The author declares no conflict of interest.

\section{References}

1. Moffat, K.; Szebenyi, D.; Bilderback, D. X-ray Laue Diffraction from Protein Crystals. Science 1984, 223, 1423-1425. [CrossRef] [PubMed]

2. Hajdu, J.; Machin, P.A.; Campbell, J.W.; Greenhough, T.J.; Clifton, I.J.; Zurek, S.; Gover, S.; Johnson, L.N.; Elder, M. Millisecond X-ray diffraction and the first electron density map from Laue photographs of a protein crystal. Nature 1987, 329, 178-181. [CrossRef] [PubMed]

3. Schlichting, I.; Almo, S.C.; Rapp, G.; Wilson, K.; Petratos, K.; Lentfer, A.; Wittinghofer, A.; Kabsch, W.; Pai, E.F.; Petsko, G.A.; et al. Time-Resolved X-ray Crystallographic Study of the Conformational Change in Ha-Ras P21 Protein on Gtp Hydrolysis. Nature 1990, 345, 309-315. [CrossRef] [PubMed]

4. Tenboer, J.; Basu, S.; Zatsepin, N.; Pande, K.; Milathianaki, D.; Frank, M.; Hunter, M.; Boutet, S.; Williams, G.J.; Koglin, J.E.; et al. Time-resolved serial crystallography captures high-resolution intermediates of photoactive yellow protein. Science 2014, 346, 1242-1246. [CrossRef] [PubMed]

5. Pande, K.; Hutchison, C.D.M.; Groenhof, G.; Aquila, A.; Robinson, J.S.; Tenboer, J.; Basu, S.; Boutet, S.; Deponte, D.; Liang, M.; et al. Femtosecond Structural Dynamics Drives the Trans/Cis Isomerization in Photoactive Yellow Protein. Science 2016, 352, 725-729. [CrossRef] [PubMed]

6. Barends, T.R.; Foucar, L.; Ardevol, A.; Nass, K.; Aquila, A.; Botha, S.; Doak, R.B.; Falahati, K.; Hartmann, E.; Hilpert, M.; et al. Direct observation of ultrafast collective motions in CO myoglobin upon ligand dissociation. Science 2015. [CrossRef]

7. Amoros, J.L.; Buerger, M.J.; de Amoros, M.L.C. The Laue Method; Academic Press: Cambridge, MA, USA, 1975.

8. Buerger, M.J. X-ray Crystallography; John Wiley and Sons: Hoboken, NJ, USA, 1949.

9. Ren, Z; Moffat, K. Quantitative-Analysis of Synchrotron Laue Diffraction Patterns in Macromolecular Crystallography. J. Appl. Crystallogr. 1995, 28, 461-481. [CrossRef]

10. Bourgeois, D. New processing tools for weak and/or spatially overlapped macromolecular diffraction patterns. Acta Crystallogr. Sect. D Biol. Crystallogr. 1999, 55, 1733-1741. [CrossRef]

11. Kirian, R.A.; Wang, X.; Weierstall, U.; Schmidt, K.E.; Spence, J.C.; Hunter, M.; Fromme, P.; White, T.; Chapman, H.N.; Holton, J. Femtosecond protein nanocrystallography-data analysis methods. Opt. Express 2010, 18, 5713-5723. [CrossRef] [PubMed] 
12. Kirian, R.A.; White, T.A.; Holton, J.M.; Chapman, H.N.; Fromme, P.; Barty, A.; Lomb, L.; Aquila, A.; Maia, F.R.; Martin, A.V.; et al. Structure-factor analysis of femtosecond microdiffraction patterns from protein nanocrystals. Acta Crystallogr. Sect. A Found. Crystallogr. 2011, 67, 131-140. [CrossRef] [PubMed]

13. Schlichting, I. Experimental phasing of serial femtosecond crystallography data. Iucrj 2017, 4, 516-517. [CrossRef] [PubMed]

14. Holton, J.M.; Frankel, K.A. The minimum crystal size needed for a complete diffraction data set. Acta Crystallogr. D 2010, 66, 393-408. [CrossRef] [PubMed]

15. Graber, T.; Anderson, S.; Brewer, H.; Chen, Y.S.; Cho, H.S.; Dashdorj, N.; Henning, R.W.; Kosheleva, I.; Macha, G.; Meron, M.; et al. BioCARS: A synchrotron resource for time-resolved X-ray science. J. Synchrotron. Radiat. 2011, 18, 658-670. [CrossRef] [PubMed]

16. Ren, Z.; Bourgeois, D.; Helliwell, J.R.; Moffat, K.; Srajer, V.; Stoddard, B.L. Laue crystallography: Coming of age. J. Synchrotron. Radiat. 1999, 6, 891-917. [CrossRef]

17. Chapman, H.N.; Fromme, P.; Barty, A.; White, T.A.; Kirian, R.A.; Aquila, A.; Hunter, M.S.; Schulz, J.; DePonte, D.P.; Weierstall, U.; et al. Femtosecond X-ray protein nanocrystallography. Nature 2011, 470, 73-77. [CrossRef] [PubMed]

18. Hunter, M.S.; DePonte, D.P.; Shapiro, D.A.; Kirian, R.A.; Wang, X.; Starodub, D.; Marchesini, S.; Weierstall, U.; Doak, R.B.; Spence, J.C.; et al. X-ray diffraction from membrane protein nanocrystals. Biophys. J. 2011, 100, 198-206. [CrossRef] [PubMed]

19. Lomb, L.; Barends, T.R.; Kassemeyer, S.; Aquila, A.; Epp, S.W.; Erk, B.; Foucar, L.; Hartmann, R.; Rudek, B.; Rolles, D.; et al. Radiation damage in protein serial femtosecond crystallography using an X-ray free-electron laser. Phys. Rev. B Condens. Matter Mater. Phys. 2011, 84, 214111. [CrossRef]

20. Chapman, H.N.; Barty, A.; Bogan, M.J.; Boutet, S.; Frank, M.; Hau-Riege, S.P.; Marchesini, S.; Woods, B.W.; Bajt, S.; Benner, H.; et al. Femtosecond diffractive imaging with a soft-X-ray free-electron laser. Nat. Phys. 2006, 2, 839-843. [CrossRef]

21. DePonte, D.P.; Weierstall, U.; Schmidt, K.; Warner, J.; Starodub, D.; Spence, J.C.H.; Doak, R.B. Gas dynamic virtual nozzle for generation of microscopic droplet streams. J. Phys. D Appl. Phys. 2008, 41, 195505. [CrossRef]

22. Barty, A.; Kirian, R.A.; Maia, F.R.N.C.; Hantke, M.; Yoon, C.H.; White, T.A.; Chapman, H. Cheetah: Software for high-throughput reduction and analysis of serial femtosecond X-ray diffraction data. J. Appl. Crystallogr. 2014, 47, 1118-1131. [CrossRef]

23. White, T.A.; Kirian, R.A.; Martin, A.V.; Aquila, A.; Nass, K.; Barty, A.; Chapman, H.N. CrystFEL: A software suite for snapshot serial crystallography. J. Appl. Crystallogr. 2012, 45, 335-341. [CrossRef]

24. Weierstall, U.; James, D.; Wang, C.; White, T.A.; Wang, D.; Liu, W.; Spence, J.C.; Bruce Doak, R.; Nelson, G.; Fromme, P.; et al. Lipidic cubic phase injector facilitates membrane protein serial femtosecond crystallography. Nat. Commun. 2014, 5, 3309. [CrossRef] [PubMed]

25. Nogly, P.; James, D.; Wang, D.; White, T.A.; Zatsepin, N.; Shilova, A.; Nelson, G.; Liu, H.; Johansson, L.; Heymann, M.; et al. Lipidic cubic phase serial millisecond crystallography using synchrotron radiation. IUCrJ 2015, 2, 168-176. [CrossRef] [PubMed]

26. Nango, E.; Royant, A.; Kubo, M.; Nakane, T.; Wickstrand, C.; Kimura, T.; Tanaka, T.; Tono, K.; Song, C.Y.; Tanaka, R.; et al. A three-dimensional movie of structural changes in bacteriorhodopsin. Science 2016, 354, 1552-1557. [CrossRef] [PubMed]

27. Ishchenko, A.; Gati, C.; Cherezov, V. Structural biology of G protein-coupled receptors: New opportunities from XFELs and cryoEM. Curr. Opin. Struct. Biol. 2018, 51, 44-52. [CrossRef]

28. Zhang, H.; Unal, H.; Gati, C.; Han, G.W.; Liu, W.; Zatsepin, N.A.; James, D.; Wang, D.; Nelson, G.; Weierstall, U.; et al. Structure of the Angiotensin receptor revealed by serial femtosecond crystallography. Cell 2015, 161, 833-844. [CrossRef] [PubMed]

29. Sugahara, M.; Mizohata, E.; Nango, E.; Suzuki, M.; Tanaka, T.; Masudala, T.; Tanaka, R.; Shimamura, T.; Tanaka, Y.; Suno, C.; et al. Grease matrix as a versatile carrier of proteins for serial crystallography. Nat. Methods 2015, 12, 61-63. [CrossRef] [PubMed]

30. Sugahara, M.; Nakane, T.; Masuda, T.; Suzuki, M.; Inoue, S.; Song, C.; Tanaka, R.; Nakatsu, T.; Mizohata, E.; Yumoto, F.; et al. Hydroxyethyl cellulose matrix applied to serial crystallography. Sci. Rep. 2017, 7, 703. [CrossRef] 
31. Edlund, P.; Takala, H.; Claesson, E.; Henry, L.; Dods, R.; Lehtivuori, H.; Panman, M.; Pande, K.; White, T.; Nakane, T.; et al. The room temperature crystal structure of a bacterial phytochrome determined by serial femtosecond crystallography. Sci. Rep. 2016, 6, 35279. [CrossRef]

32. Woitowich, N.C.; Halavaty, A.S.; Waltz, P.; Kupitz, C.; Valera, J.; Tracy, G.; Gallagher, K.D.; Claesson, E.; Nakane, T.; Pandey, S.; et al. Structural basis for light control of cell development revealed by crystal structures of a myxobacterial phytochrome. IUCrJ 2018, 5, 619-634. [CrossRef]

33. Suga, M.; Akita, F.; Sugahara, M.; Kubo, M.; Nakajima, Y.; Nakane, T.; Yamashita, K.; Umena, Y.; Nakabayashi, M.; Yamane, T.; et al. Light-induced structural changes and the site of $\mathrm{O}=\mathrm{O}$ bond formation in PSII caught by XFEL. Nature 2017, 543, 131-135. [CrossRef] [PubMed]

34. Sierra, R.G.; Gati, C.; Laksmono, H.; Dao, E.H.; Gul, S.; Fuller, F.; Kern, J.; Chatterjee, R.; Ibrahim, M.; Brewster, A.S.; et al. Concentric-flow electrokinetic injector enables serial crystallography of ribosome and photosystem II. Nat. Methods 2016, 13, 59. [CrossRef] [PubMed]

35. Greiffenberg, D.; Collaboration, A. The AGIPD detector for the European XFEL. J. Instrum. 2012, 7. [CrossRef]

36. Wiedorn, M.O.; Oberthur, D.; Bean, R.; Schubert, R.; Werner, N.; Abbey, B.; Aepfelbacher, M.; Adriano, L.; Allahgholi, A.; Al-Qudami, N.; et al. Megahertz serial crystallography. Nat. Commun. 2018, 9, 4025. [CrossRef] [PubMed]

37. Grunbein, M.L.; Bielecki, J.; Gorel, A.; Stricker, M.; Bean, R.; Cammarata, M.; Dorner, K.; Frohlich, L.; Hartmann, E.; Hauf, S.; et al. Megahertz data collection from protein microcrystals at an X-ray free-electron laser. Nat. Commun. 2018, 9, 3487. [CrossRef] [PubMed]

38. Stan, C.A.; Milathianaki, D.; Laksmono, H.; Sierra, R.G.; McQueen, T.A.; Messerschmidt, M.; Williams, G.J.; Koglin, J.E.; Lane, T.J.; Hayes, M.J.; et al. Liquid explosions induced by X-ray laser pulses. Nat. Phys. 2016, 12, 966-971. [CrossRef]

39. Wiedorn, M.O.; Awel, S.; Morgan, A.J.; Ayyer, K.; Gevorkov, Y.; Fleckenstein, H.; Roth, N.; Adriano, L.; Bean, R.; Beyerlein, K.R.; et al. Rapid sample delivery for megahertz serial crystallography at X-ray FELs. IUCrJ 2018, 5, 574-584. [CrossRef] [PubMed]

40. Roedig, P.; Vartiainen, I.; Duman, R.; Panneerselvam, S.; Stube, N.; Lorbeer, O.; Warmer, M.; Sutton, G.; Stuart, D.I.; Weckert, E.; et al. A micro-patterned silicon chip as sample holder for macromolecular crystallography experiments with minimal background scattering. Sci. Rep. 2015, 5, 10451. [CrossRef] [PubMed]

41. Roessler, C.G.; Agarwal, R.; Allaire, M.; Alonso-Mori, R.; Andi, B.; Bachega, J.F.; Bommer, M.; Brewster, A.S.; Browne, M.C.; Chatterjee, R.; et al. Acoustic Injectors for Drop-On-Demand Serial Femtosecond Crystallography. Structure 2016, 24, 631-640. [CrossRef]

42. Schmidt, M.; Rajagopal, S.; Ren, Z.; Moffat, K. Application of singular value decomposition to the analysis of time-resolved macromolecular X-ray data. Biophys. J. 2003, 84, 2112-2129. [CrossRef]

43. Schmidt, M. Structure Based Enzyme Kinetics by Time-Resolved X-ray Crystallography. In Ultrashort Laser Pulses in Medicine and Biology; Springer: Berlin, Germany; New York, NY, USA, 2008.

44. Srajer, V.; Schmidt, M. Watching proteins function with time-resolved X-ray crystallography. J. Phys. D Appl. Phys. 2017, 50, 373001. [CrossRef]

45. Steinfeld, J.I.; Francisco, J.S.; Hase, W.L. Chemical Kinetics and Dynamics, 2nd ed.; Prentience Hall: Upper Saddle River, NJ, USA, 1985.

46. Groenhof, G. Introduction to QM/MM Simulations. Methods Mol. Biol. 2013, 924, 43-66. [CrossRef] [PubMed]

47. Martin-Garcia, J.M.; Conrad, C.E.; Nelson, G.; Stander, N.; Zatsepin, N.A.; Zook, J.; Zhu, L.; Geiger, J.; Chun, E.; Kissick, D.; et al. Serial millisecond crystallography of membrane and soluble protein microcrystals using synchrotron radiation. IUCrJ 2017, 4, 439-454. [CrossRef] [PubMed]

48. Glownia, J.M.; Cryan, J.; Andreasson, J.; Belkacem, A.; Berrah, N.; Blaga, C.I.; Bostedt, C.; Bozek, J.; DiMauro, L.F.; Fang, L.; et al. Time-resolved pump-probe experiments at the LCLS. Opt. Express 2010, 18, 17620-17630. [CrossRef] [PubMed]

49. Hartmann, N.; Helml, W.; Galler, A.; Bionta, M.R.; Grunert, J.; Molodtsov, S.L.; Ferguson, K.R.; Schorb, S.; Swiggers, M.L.; Carron, S.; et al. Sub-femtosecond precision measurement of relative X-ray arrival time for free-electron lasers. Nat. Photonics 2014, 8, 706-709. [CrossRef]

50. Harmand, M.; Coffee, R.; Bionta, M.R.; Chollet, M.; French, D.; Zhu, D.; Fritz, D.M.; Lemke, H.T.; Medvedev, N.; Ziaja, B.; et al. Achieving few-femtosecond time-sorting at hard X-ray free-electron lasers. Nat. Photonics 2013, 7, 215-218. [CrossRef] 
51. Powell, H.R. X-ray data processing. Biosci. Rep 2017, 37. [CrossRef]

52. Hart, P.; Boutet, S.; Gabriella, C.; Dubrovin, M.; Duda, B.; Fritz, D.; Haller, G.; Herbst, R.; Herrmann, S.; Kenney, C.; et al. The CSPAD megapixel X-ray camera at LCLS. Proc. SPIE 2012, 8504, 85040C.

53. Bionta, M.R.; Lemke, H.T.; Cryan, J.P.; Glownia, J.M.; Bostedt, C.; Cammarata, M.; Castagna, J.C.; Ding, Y.; Fritz, D.M.; Fry, A.R.; et al. Spectral encoding of X-ray/optical relative delay. Opt. Express 2011, 19, 21855-21865. [CrossRef] [PubMed]

54. White, T.A.; Mariani, V.; Brehm, W.; Yefanov, O.; Barty, A.; Beyerlein, K.R.; Chervinskii, F.; Galli, L.; Gati, C.; Nakane, T.; et al. Recent developments in CrystFEL. J. Appl. Crystallogr. 2016, 49, 680-689. [CrossRef] [PubMed]

55. Brehm, W.; Diederichs, K. Breaking the indexing ambiguity in serial crystallography. Acta Crystallogr. Sect. D Biol. Crystallogr. 2014, 70, 101-109. [CrossRef]

56. Efremov, R.; Moukhametzianov, R.; Buldt, G.; Gordeliy, V. Physical detwinning of hemihedrally twinned hexagonal crystals of bacteriorhodopsin. Biophys. J. 2004, 87, 3608-3613. [CrossRef]

57. Winn, M.D.; Ballard, C.C.; Cowtan, K.D.; Dodson, E.J.; Emsley, P.; Evans, P.R.; Keegan, R.M.; Krissinel, E.B.; Leslie, A.G.W.; McCoy, A.; et al. Overview of the CCP4 suite and current developments. Acta Crystallogr. D 2011, 67, 235-242. [CrossRef] [PubMed]

58. Schmidt, M.; Srajer, V.; Henning, R.; Ihee, H.; Purwar, N.; Tenboer, J.; Tripathi, S. Protein energy landscapes determined by five-dimensional crystallography. Acta Crystallogr. Sect. D Biol. Crystallogr. 2013, 69, 2534-2542. [CrossRef] [PubMed]

59. Genick, U.K.; Borgstahl, G.E.; Ng, K.; Ren, Z.; Pradervand, C.; Burke, P.M.; Srajer, V.; Teng, T.Y.; Schildkamp, W.; McRee, D.E.; et al. Structure of a protein photocycle intermediate by millisecond time-resolved crystallography. Science 1997, 275, 1471-1475. [CrossRef] [PubMed]

60. Tripathi, S.; Srajer, V.; Purwar, N.; Henning, R.; Schmidt, M. pH dependence of the photoactive yellow protein photocycle investigated by time-resolved crystallography. Biophys. J. 2012, 102, 325-332. [CrossRef] [PubMed]

61. Henderson, R.; Moffat, K. The difference Fourier technique in protein crystallography: Errors and their treatment. Acta Crystallogr. B 1971, 27, 1414-1420. [CrossRef]

62. Schmidt, M.; Srajer, V.; Purwar, N.; Tripathi, S. The kinetic dose limit in room-temperature time-resolved macromolecular crystallography. J. Synchrotron. Radiat. 2012, 19, 264-273. [CrossRef]

63. Emsley, P.; Lohkamp, B.; Scott, W.G.; Cowtan, K. Features and development of Coot. Acta Crystallogr. Sect. D Biol. Crystallogr. 2010, 66, 486-501. [CrossRef] [PubMed]

64. Olmos, J.L., Jr.; Pandey, S.; Martin-Garcia, J.M.; Calvey, G.; Katz, A.; Knoska, J.; Kupitz, C.; Hunter, M.S.; Liang, M.; Oberthuer, D.; et al. Enzyme intermediates captured "on the fly" by mix-and-inject serial crystallography. BMC Biol. 2018, 16, 59. [CrossRef] [PubMed]

65. Ihee, H.; Rajagopal, S.; Srajer, V.; Pahl, R.; Anderson, S.; Schmidt, M.; Schotte, F.; Anfinrud, P.A.; Wulff, M.; Moffat, K. Visualizing reaction pathways in photoactive yellow protein from nanoseconds to seconds. Proc. Natl. Acad. Sci. USA 2005, 102, 7145-7150. [CrossRef]

66. Schmidt, M.; Nienhaus, K.; Pahl, R.; Krasselt, A.; Anderson, S.; Parak, F.; Nienhaus, G.U.; Srajer, V. Ligand migration pathway and protein dynamics in myoglobin: A time-resolved crystallographic study on L29W MbCO. Proc. Natl. Acad. Sci. USA 2005, 102, 11704-11709. [CrossRef] [PubMed]

67. Jung, Y.O.; Lee, J.H.; Kim, J.; Schmidt, M.; Moffat, K.; Srajer, V.; Ihee, H. Volume-conserving trans-cis isomerization pathways in photoactive yellow protein visualized by picosecond X-ray crystallography. Nat. Chem. 2013, 5, 212-220. [CrossRef]

68. Rajagopal, S.; Schmidt, M.; Anderson, S.; Ihee, H.; Moffat, K. Analysis of experimental time-resolved crystallographic data by singular value decomposition. Acta Crystallogr. Sect. D Biol. Crystallogr. 2004, 60, 860-871. [CrossRef] [PubMed]

69. Schmidt, M.; Pahl, R.; Srajer, V.; Anderson, S.; Ren, Z.; Ihee, H.; Rajagopal, S.; Moffat, K. Protein kinetics: Structures of intermediates and reaction mechanism from time-resolved X-ray data. Proc. Natl. Acad. Sci. USA 2004, 101, 4799-4804. [CrossRef] [PubMed]

70. Schmidt, M. Time-Resolved Macromolecular Crystallography at Modern X-ray Sources. Methods Mol. Biol. 2017, 1607, 273-294. [CrossRef] [PubMed] 
71. Levantino, M.; Schiro, G.; Lemke, H.T.; Cottone, G.; Glownia, J.M.; Zhu, D.; Chollet, M.; Ihee, H.; Cupane, A.; Cammarata, M. Ultrafast myoglobin structural dynamics observed with an X-ray free-electron laser. Nat. Commun. 2015, 6, 6772. [CrossRef] [PubMed]

72. Arnlund, D.; Johansson, L.C.; Wickstrand, C.; Barty, A.; Williams, G.J.; Malmerberg, E.; Davidsson, J.; Milathianaki, D.; DePonte, D.P.; Shoeman, R.L.; et al. Visualizing a protein quake with time-resolved X-ray scattering at a free-electron laser. Nat. Methods 2014, 11, 923-926. [CrossRef] [PubMed]

73. Fung, R.; Hanna, A.M.; Vendrell, O.; Ramakrishna, S.; Seideman, T.; Santra, R.; Ourmazd, A.; Ourmazd, A. Dynamics from noisy data with extreme timing uncertainty. Nature 2016, 532, 471-475. [CrossRef] [PubMed]

74. Meyer, T.E. Isolation and characterization of soluble cytochromes, ferredoxins and other chromophoric proteins from the halophilic phototrophic bacterium Ectothiorhodospira halophila. Biochim. Biophys. Acta 1985, 806, 175-183. [CrossRef]

75. Schmidt, M. A short history of structure based research on the photocycle of photoactive yellow protein. Struct. Dyn. 2017, 4, 032201. [CrossRef] [PubMed]

76. Perman, B.; Srajer, V.; Ren, Z.; Teng, T.Y.; Pradervand, C.; Ursby, T.; Bourgeois, D.; Schotte, F.; Wulff, M.; Kort, R.; et al. Energy transduction on the nanosecond time scale: Early structural events in a xanthopsin photocycle. Science 1998, 279, 1946-1950. [CrossRef] [PubMed]

77. Schotte, F.; Cho, H.S.; Kaila, V.R.; Kamikubo, H.; Dashdorj, N.; Henry, E.R.; Graber, T.J.; Henning, R.; Wulff, M.; Hummer, G.; et al. Watching a signaling protein function in real time via 100-ps time-resolved Laue crystallography. Proc. Natl. Acad. Sci. USA 2012, 109, 19256-19261. [CrossRef] [PubMed]

78. Sprenger, W.W.; Hoff, W.D.; Armitage, J.P.; Hellingwerf, K.J. The Eubacterium Ectothiorhodospira-Halophila Is Negatively Phototactic, with a Wavelength Dependence That Fits the Absorption-Spectrum of the Photoactive Yellow Protein. J. Bacteriol. 1993, 175, 3096-3104. [CrossRef] [PubMed]

79. Kort, R.; Vonk, H.; Xu, X.; Hoff, W.D.; Crielaard, W.; Hellingwerf, K.J. Evidence for trans-cis isomerization of the p-coumaric acid chromophore as the photochemical basis of the photocycle of photoactive yellow protein. FEBS Lett. 1996, 382, 73-78. [CrossRef]

80. van Thor, J.J.; Warren, M.M.; Lincoln, C.N.; Chollet, M.; Lemke, H.T.; Fritz, D.M.; Schmidt, M.; Tenboer, J.; Ren, Z.; Srajer, V.; et al. Signal to noise considerations for single crystal femtosecond time resolved crystallography of the Photoactive Yellow Protein. Faraday Discuss. 2014, 171, 439-455. [CrossRef] [PubMed]

81. Hutchison, C.D.M.; van Thor, J.J. Populations and coherence in femtosecond time resolved X-ray crystallography of the photoactive yellow protein. Int. Rev. Phys. Chem. 2017, 36, 117-143. [CrossRef]

82. Prokhorenko, V.I.; Nagy, A.M.; Waschuk, S.A.; Brown, L.S.; Birge, R.R.; Miller, R.J. Coherent control of retinal isomerization in bacteriorhodopsin. Science 2006, 313, 1257-1261. [CrossRef] [PubMed]

83. Austin, R.H.; Beeson, K.W.; Eisenstein, L.; Frauenfelder, H.; Gunsalus, I.C. Dynamics of ligand binding to myoglobin. Biochemistry 1975, 14, 5355-5373. [CrossRef] [PubMed]

84. Ostermann, A.; Waschipky, R.; Parak, F.G.; Nienhaus, G.U. Ligand binding and conformational motions in myoglobin. Nature 2000, 404, 205-208. [CrossRef]

85. Srajer, V.; Teng, T.Y.; Ursby, T.; Pradervand, C.; Ren, Z.; Adachi, S.; Schildkamp, W.; Bourgeois, D.; Wulff, M.; Moffat, K. Photolysis of the carbon monoxide complex of myoglobin: Nanosecond time-resolved crystallography. Science 1996, 274, 1726-1729. [CrossRef] [PubMed]

86. Schlichting, I.; Berendzen, J.; Phillips, G.N.; Sweet, R.M. Crystal-Structure of Photolyzed Carbonmonoxy-Myoglobin. Nature 1994, 371, 808-812. [CrossRef] [PubMed]

87. Schotte, F.; Lim, M.; Jackson, T.A.; Smirnov, A.V.; Soman, J.; Olson, J.S.; Phillips, G.N., Jr.; Wulff, M.; Anfinrud, P.A. Watching a protein as it functions with 150-ps time-resolved X-ray crystallography. Science 2003, 300, 1944-1947. [CrossRef]

88. Bourgeois, D.; Vallone, B.; Schotte, F.; Arcovito, A.; Miele, A.E.; Sciara, G.; Wulff, M.; Anfinrud, P.; Brunori, M. Complex landscape of protein structural dynamics unveiled by nanosecond Laue crystallography. Proc. Natl. Acad. Sci. USA 2003, 100, 8704-8709. [CrossRef]

89. Lim, M.; Jackson, T.A.; Anfinrud, P.A. Binding of CO to myoglobin from a heme pocket docking site to form nearly linear Fe-C-O. Science 1995, 269, 962-966. [CrossRef]

90. Genberg, L.; Richard, L.; McLendon, G.; Miller, R.J. Direct observation of global protein motion in hemoglobin and myoglobin on picosecond time scales. Science 1991, 251, 1051-1054. [CrossRef] [PubMed]

91. Einsle, O.; Messerschmidt, A.; Stach, P.; Bourenkov, G.P.; Bartunik, H.D.; Huber, R.; Kroneck, P.M.H. Structure of cytochrome c nitrite reductase. Nature 1999, 400, 476-480. [CrossRef] [PubMed] 
92. Youngblut, M.; Judd, E.T.; Srajer, V.; Sayyed, B.; Goelzer, T.; Elliott, S.J.; Schmidt, M.; Pacheco, A.A. Laue crystal structure of Shewanella oneidensis cytochrome c nitrite reductase from a high-yield expression system. J. Biol. Inorg. Chem. 2012, 17, 647-662. [CrossRef]

93. Kupitz, C.; Basu, S.; Grotjohann, I.; Fromme, R.; Zatsepin, N.A.; Rendek, K.N.; Hunter, M.S.; Shoeman, R.L.; White, T.A.; Wang, D.; et al. Serial time-resolved crystallography of photosystem II using a femtosecond X-ray laser. Nature 2014, 513, 5. [CrossRef] [PubMed]

94. Young, I.D.; Ibrahim, M.; Chatterjee, R.; Gul, S.; Fuller, F.; Koroidov, S.; Brewster, A.S.; Tran, R.; Alonso-Mori, R.; Kroll, T.; et al. Structure of photosystem II and substrate binding at room temperature. Nature 2016, 540, 453-457. [CrossRef] [PubMed]

95. Shimada, A.; Kubo, M.; Baba, S.; Yamashita, K.; Hirata, K.; Ueno, G.; Nomura, T.; Kimura, T.; Shinzawa-Itoh, K.; Baba, J.; et al. A nanosecond time-resolved XFEL analysis of structural changes associated with CO release from cytochrome c oxidase. Sci. Adv. 2017, 3, e1603042. [CrossRef] [PubMed]

96. Schmidt, M.; Meier, B.; Parak, F. X-ray structure of the cambialistic superoxide dismutase from Propionibacterium shermanii active with Fe or Mn. J. Biol. Inorg. Chem. 1996, 1, 532-541. [CrossRef]

97. Sheng, Y.; Abreu, I.A.; Cabelli, D.E.; Maroney, M.J.; Miller, A.F.; Teixeira, M.; Valentine, J.S. Superoxide dismutases and superoxide reductases. Chem. Rev. 2014, 114, 3854-3918. [CrossRef]

98. Mangani, S. Textbook of Metalloproteins, Metal Ion Routes between Organisms and the Inorganic World; World Scientific Publishing: Singapore, 2020. [CrossRef]

99. Taberman, H. Radiation Damage in Macromolecular Crystallography-An Experimentalist's View. Crystals 2018, 8, 157. [CrossRef]

100. Nass, K.; Foucar, L.; Barends, T.R.; Hartmann, E.; Botha, S.; Shoeman, R.L.; Doak, R.B.; Alonso-Mori, R.; Aquila, A.; Bajt, S.; et al. Indications of radiation damage in ferredoxin microcrystals using high-intensity X-FEL beams. J. Synchrotron. Radiat. 2015, 22, 225-238. [CrossRef] [PubMed]

101. Umena, Y.; Kawakami, K.; Shen, J.R.; Kamiya, N. Crystal structure of oxygen-evolving photosystem II at a resolution of 1.9 A. Nature 2011, 473, 55-60. [CrossRef] [PubMed]

102. Suga, M.; Akita, F.; Hirata, K.; Ueno, G.; Murakami, H.; Nakajima, Y.; Shimizu, T.; Yamashita, K.; Yamamoto, M.; Ago, H.; et al. Native structure of photosystem II at 1.95 A resolution viewed by femtosecond X-ray pulses. Nature 2015, 517, 99-103. [CrossRef] [PubMed]

103. Kern, J.; Chatterjee, R.; Young, I.D.; Fuller, F.D.; Lassalle, L.; Ibrahim, M.; Gul, S.; Fransson, T.; Brewster, A.S.; Alonso-Mori, R.; et al. Structures of the intermediates of Kok's photosynthetic water oxidation clock. Nature 2018, 563, 421-425. [CrossRef]

104. Beyerlein, K.R.; Dierksmeyer, D.; Mariani, V.; Kuhn, M.; Sarrou, I.; Ottaviano, A.; Awel, S.; Knoska, J.; Fuglerud, S.; Jonsson, O.; et al. Mix-and-diffuse serial synchrotron crystallography. IUCrJ 2017, 4, 769-777. [CrossRef]

105. Stellato, F.; Oberthuer, D.; Mengning, L.; Bean, R.; Gati, C.; Yefanov, O.; Barty, A.; Burkhardt, A.; Fischer, P.; Galli, L.; et al. Room-temperature macromolecular serial crystallography using synchrotron radiation. $\mathrm{IUCrJ}$ 2014, 1, 204-212. [CrossRef]

106. Meents, A.; Wiedorn, M.O.; Srajer, V.; Henning, R.; Sarrou, I.; Bergtholdt, J.; Barthelmess, M.; Reinke, P.Y.A.; Dierksmeyer, D.; Tolstikova, A.; et al. Pink-beam serial crystallography. Nat. Commun. 2017, 8, 1281. [CrossRef] [PubMed]

107. Goelder, M.; Givens, R. Dynamic Studies in Biology: Phototriggers, Photoswitches and Caged Biomolecules; Wiley VCH: Hoboken, NJ, USA, 2005.

108. Stoddard, B.L.; Cohen, B.E.; Brubaker, M.; Mesecar, A.D.; Koshland, D.E., Jr. Millisecond Laue structures of an enzyme-product complex using photocaged substrate analogs. Nat. Struct. Biol. 1998, 5, 891-897. [CrossRef]

109. Schlichting, I.; Rapp, G.; John, J.; Wittinghofer, A.; Pai, E.F.; Goody, R.S. Biochemical and crystallographic characterization of a complex of c-Ha-ras p21 and caged GTP with flash photolysis. Proc. Natl. Acad. Sci. USA 1989, 86, 7687-7690. [CrossRef] [PubMed]

110. Moglich, A.; Moffat, K. Engineered photoreceptors as novel optogenetic tools. Photochem. Photobiol. Sci. 2010, 9, 1286-1300. [CrossRef]

111. Moffat, K. Time-resolved crystallography and protein design: Signalling photoreceptors and optogenetics. Philos. Trans. R. Soc. Lond. Ser. B Biol. Sci. 2014, 369. [CrossRef] [PubMed]

112. Weinberg, R.A. The Biology of Cancer; Garland Science: New York, NY, USA, 2007. 
113. Wyckoff, H.W.; Doscher, M.; Tsernoglou, D.; Inagami, T.; Johnson, L.N.; Hardman, K.D.; Allewell, N.M.; Kelly, D.M.; Richards, F.M. Design of a diffractometer and flow cell system for X-ray analysis of crystalline proteins with applications to the crystal chemistry of ribonuclease-S. J. Mol. Biol. 1967, 27, 563-578. [CrossRef]

114. Perry, S.L.; Guha, S.; Pawate, A.S.; Henning, R.; Kosheleva, I.; Srajer, V.; Kenis, P.J.; Ren, Z. In situ serial Laue diffraction on a microfluidic crystallization device. J. Appl. Crystallogr. 2014, 47, 1975-1982. [CrossRef] [PubMed]

115. Helliwell, J.R.; Nieh, Y.P.; Raftery, J.; Cassetta, A.; Habash, J.; Carr, P.D.; Ursby, T.; Wulff, M.; Thompson, A.W.; Niemann, A.C.; et al. Time-resolved structures of hydroxymethylbilane synthase (Lys59Gln mutant) as it is loaded with substrate in the crystal determined by Laue diffraction. J. Chem. Soc. Faraday Trans. 1998, 94, 2615-2622. [CrossRef]

116. Kim, T.H.; Mehrabi, P.; Ren, Z.; Sljoka, A.; Ing, C.; Bezginov, A.; Ye, L.; Pomes, R.; Prosser, R.S.; Pai, E.F. The role of dimer asymmetry and protomer dynamics in enzyme catalysis. Science 2017, 355. [CrossRef] [PubMed]

117. Blake, C.C.; Koenig, D.F.; Mair, G.A.; North, A.C.; Phillips, D.C.; Sarma, V.R. Structure of hen egg-white lysozyme. A three-dimensional Fourier synthesis at 2 Angstrom resolution. Nature 1965, 206, 757-761. [CrossRef] [PubMed]

118. Sainsbury, S.; Bird, L.; Rao, V.; Shepherd, S.M.; Stuart, D.I.; Hunter, W.N.; Owens, R.J.; Ren, J. Crystal structures of penicillin-binding protein 3 from Pseudomonas aeruginosa: Comparison of native and antibiotic-bound forms. J. Mol. Biol. 2011, 405, 173-184. [CrossRef] [PubMed]

119. Fair, R.J.; Tor, Y. Antibiotics and bacterial resistance in the 21st century. Perspect. Med. Chem. 2014, 6, $25-64$. [CrossRef]

120. Bassetti, M.; Merelli, M.; Temperoni, C.; Astilean, A. New antibiotics for bad bugs: Where are we? Ann. Clin. Microbiol. Antimicrob. 2013, 12, 22. [CrossRef]

121. Walsh, C. Molecular mechanisms that confer antibacterial drug resistance. Nature 2000, 406, 775-781. [CrossRef]

122. Kong, K.F.; Schneper, L.; Mathee, K. Beta-lactam antibiotics: From antibiosis to resistance and bacteriology. APMIS 2010, 118, 1-36. [CrossRef] [PubMed]

123. Ambler, R.P. The structure of beta-lactamases. Philos. Trans. R. Soc. Lond. Ser. B Biol. Sci. 1980, 289, 321-331. [CrossRef] [PubMed]

124. Kupitz, C.; Olmos, J.L., Jr.; Holl, M.; Tremblay, L.; Pande, K.; Pandey, S.; Oberthur, D.; Hunter, M.; Liang, M.; Aquila, A.; et al. Structural enzymology using X-ray free electron lasers. Struct. Dyn. 2017, 4, 044003. [CrossRef] [PubMed]

125. Carslaw, H.S.; Jaeger, J.C. Conduction Heat in Solids, 2nd ed.; Clarendon Press: Oxford, UK, 1959.

126. Calvey, G.D.; Katz, A.M.; Schaffer, C.B.; Pollack, L. Mixing injector enables time-resolved crystallography with high hit rate at X-ray free electron lasers. Struct. Dyn. 2016, 3, 054301. [CrossRef] [PubMed]

127. Kiener, P.A.; Waley, S.G. Reversible inhibitors of penicillinases. Biochem. J. 1978, 169, 197-204. [CrossRef] [PubMed]

128. Kang, Y.; Zhou, X.E.; Gao, X.; He, Y.; Liu, W.; Ishchenko, A.; Barty, A.; White, T.A.; Yefanov, O.; Han, G.W.; et al. Crystal structure of rhodopsin bound to arrestin by femtosecond X-ray laser. Nature 2015, 523, 561-567. [CrossRef] [PubMed]

129. Wald, G. Molecular basis of visual excitation. Science 1968, 162, 230-239. [CrossRef] [PubMed]

130. Ernst, O.P.; Lodowski, D.T.; Elstner, M.; Hegemann, P.; Brown, L.S.; Kandori, H. Microbial and animal rhodopsins: Structures, functions, and molecular mechanisms. Chem. Rev. 2014, 114, 126-163. [CrossRef] [PubMed]

131. Stoeckenius, W.; Lozier, R.H.; Bogomolni, R.A. Bacteriorhodopsin and the purple membrane of halobacteria. Biochim. Biophys. Acta 1979, 505, 215-278. [CrossRef]

132. Kuhlbrandt, W. Bacteriorhodopsin-The movie. Nature 2000, 406, 569-570. [CrossRef] [PubMed]

133. Landau, E.M.; Rosenbusch, J.P. Lipidic cubic phases: A novel concept for the crystallization of membrane proteins. Proc. Natl. Acad. Sci. USA 1996, 93, 14532-14535. [CrossRef]

134. Pebay-Peyroula, E.; Rummel, G.; Rosenbusch, J.P.; Landau, E.M. X-ray structure of bacteriorhodopsin at 2.5 angstroms from microcrystals grown in lipidic cubic phases. Science 1997, 277, 1676-1681. [CrossRef] [PubMed] 
135. Luecke, H.; Schobert, B.; Richter, H.T.; Cartailler, J.P.; Lanyi, J.K. Structure of bacteriorhodopsin at 1.55 A resolution. J. Mol. Biol. 1999, 291, 899-911. [CrossRef] [PubMed]

136. Nogly, P.; Weinert, T.; James, D.; Carbajo, S.; Ozerov, D.; Furrer, A.; Gashi, D.; Borin, V.; Skopintsev, P.; Jaeger, K.; et al. Retinal isomerization in bacteriorhodopsin captured by a femtosecond X-ray laser. Science 2018, 361. [CrossRef]

137. Butler, W.L.; Norris, K.H.; Siegelman, H.W.; Hendricks, S.B. Detection, assay, and preliminary purification of the pigment controlling photoresponsive development of plants. Proc. Natl. Acad. Sci. USA 1959, 89, 6. [CrossRef]

138. Auldridge, M.E.; Forest, K.T. Bacterial phytochromes: More than meets the light. Crit. Rev. Biochem. Mol. 2011, 46, 67-88. [CrossRef] [PubMed]

139. Batschauer, A. Photoreceptors of higher plants. Planta 1998, 206, 479-492. [CrossRef] [PubMed]

140. Davis, S.J.; Vener, A.V.; Vierstra, R.D. Bacteriophytochromes: Phytochrome-like photoreceptors from nonphotosynthetic eubacteria. Science 1999, 286, 2517-2520. [CrossRef] [PubMed]

141. Wagner, J.R.; Brunzelle, J.S.; Forest, K.T.; Vierstra, R.D. A light-sensing knot revealed by the structure of the chromophore-binding domain of phytochrome. Nature 2005, 438, 325-331. [CrossRef]

142. Gourinchas, G.; Etzl, S.; Gobl, C.; Vide, U.; Madl, T.; Winkler, A. Long-range allosteric signaling in red light-regulated diguanylyl cyclases. Sci. Adv. 2017, 3, e1602498. [CrossRef] [PubMed]

143. Otero, L.H.; Klinke, S.; Rinaldi, J.; Velazquez-Escobar, F.; Mroginski, M.A.; Fernandez Lopez, M.; Malamud, F.; Vojnov, A.A.; Hildebrandt, P.; Goldbaum, F.A.; et al. Structure of the Full-Length Bacteriophytochrome from the Plant Pathogen Xanthomonas campestris Provides Clues to its Long-Range Signaling Mechanism. J. Mol. Biol. 2016, 428, 3702-3720. [CrossRef] [PubMed]

144. Burgie, E.S.; Bussell, A.N.; Walker, J.M.; Dubiel, K.; Vierstra, R.D. Crystal structure of the photosensing module from a red/far-red light-absorbing plant phytochrome. Proc. Natl. Acad. Sci. USA 2014, 111, 10179-10184. [CrossRef] [PubMed]

145. Wagner, J.R.; Zhang, J.; von Stetten, D.; Gunther, M.; Murgida, D.H.; Mroginski, M.A.; Walker, J.M.; Forest, K.T.; Hildebrandt, P.; Vierstra, R.D. Mutational analysis of Deinococcus radiodurans bacteriophytochrome reveals key amino acids necessary for the photochromicity and proton exchange cycle of phytochromes. J. Biol. Chem. 2008, 283, 12212-12226. [CrossRef] [PubMed]

146. Takala, H.; Bjorling, A.; Berntsson, O.; Lehtivuori, H.; Niebling, S.; Hoernke, M.; Kosheleva, I.; Henning, R.; Menzel, A.; Ihalainen, J.A.; et al. Signal amplification and transduction in phytochrome photosensors. Nature 2014, 509, 245-248. [CrossRef]

147. Burgie, E.S.; Zhang, J.; Vierstra, R.D. Crystal Structure of Deinococcus Phytochrome in the Photoactivated State Reveals a Cascade of Structural Rearrangements during Photoconversion. Structure 2016, 24, 448-457. [CrossRef]

148. Stagno, J.R.; Liu, Y.; Bhandari, Y.R.; Conrad, C.E.; Panja, S.; Swain, M.; Fan, L.; Nelson, G.; Li, C.; Wendel, D.R.; et al. Structures of riboswitch RNA reaction states by mix-and-inject XFEL serial crystallography. Nature 2017, 541, 242-246. [CrossRef]

149. Toh, K.C.; Stojkovic, E.A.; van Stokkum, I.H.M.; Moffat, K.; Kennis, J.T.M. Fluorescence quantum yield and photochemistry of bacteriophytochrome constructs. Phys. Chem. Chem. Phys. 2011, 13, 11985-11997. [CrossRef] [PubMed]

150. Shu, X.; Royant, A.; Lin, M.Z.; Aguilera, T.A.; Lev-Ram, V.; Steinbach, P.A.; Tsien, R.Y. Mammalian expression of infrared fluorescent proteins engineered from a bacterial phytochrome. Science 2009, 324, 804-807. [CrossRef] [PubMed]

151. Sahl, S.J.; Hell, S.W.; Jakobs, S. Fluorescence nanoscopy in cell biology. Nat. Rev. Mol. Cell Biol. 2017, 18, 685-701. [CrossRef] [PubMed]

152. Stauch, B.; Johansson, L.; Ishchenko, A.; Han, G.W.; Batyuk, A.; Cherezov, V. Advances in Structure Determination of G Protein-Coupled Receptors by SFX. In X-ray Free Electron Lasers; Boutet, S., Fromme, P., Hunter, M., Eds.; Springer Nature: Cham, Switzerland, 2018; pp. 301-329.

(C) 2019 by the author. Licensee MDPI, Basel, Switzerland. This article is an open access article distributed under the terms and conditions of the Creative Commons Attribution (CC BY) license (http:// creativecommons.org/licenses/by/4.0/). 